\title{
Global and regional estimates of cancer mortality and incidence by site: I. Application of regional cancer survival model to estimate cancer mortality distribution by site \\ Colin D Mathers*1, Kenji Shibuya1, Cynthia Boschi-Pinto², Alan D Lopez ${ }^{1}$ and Christopher JL Murray ${ }^{3}$
}

Address: ${ }^{1}$ Global Programme on Evidence for Health Policy, World Health Organization, Geneva, Switzerland, ${ }^{2}$ Family and Community Health/ Child and Adolescent Health and Development, World Health Organization, Geneva, Switzerland and ${ }^{3}$ Executive Director, Evidence and Information for Policy, World Health Organization, Geneva, Switzerland

Email: Colin D Mathers* - mathersc@who.ch; Kenji Shibuya - shibuyak@who.int; Cynthia Boschi-Pinto - pintoc@who.ch; Alan D Lopez - lopeza@who.ch; Christopher JL Murray - murrayc@who.ch

* Corresponding author

Published: 26 December 2002

BMC Cancer 2002, 2:36
Received: 22 April 2002

Accepted: 26 December 2002

This article is available from: http://www.biomedcentral.com/I47I-2407/2/36

(c) 2002 Mathers et al; licensee BioMed Central Ltd. This is an Open Access article: verbatim copying and redistribution of this article are permitted in all media for any purpose, provided this notice is preserved along with the article's original URL.

\begin{abstract}
Background: The Global Burden of Disease 2000 (GBD 2000) study starts from an analysis of the overall mortality envelope in order to ensure that the cause-specific estimates add to the total all cause mortality by age and sex. For regions where information on the distribution of cancer deaths is not available, a site-specific survival model was developed to estimate the distribution of cancer deaths by site.
\end{abstract}

Methods: An age-period-cohort model of cancer survival was developed based on data from the Surveillance, Epidemiology, and End Results (SEER). The model was further adjusted for the level of economic development in each region. Combined with the available incidence data, cancer death distributions were estimated and the model estimates were validated against vital registration data from regions other than the United States.

Results: Comparison with cancer mortality distribution from vital registration confirmed the validity of this approach. The model also yielded the cancer mortality distribution which is consistent with the estimates based on regional cancer registries. There was a significant variation in relative interval survival across regions, in particular for cancers of bladder, breast, melanoma of the skin, prostate and haematological malignancies. Moderate variations were observed among cancers of colon, rectum, and uterus. Cancers with very poor prognosis such as liver, lung, and pancreas cancers showed very small variations across the regions.

Conclusions: The survival model presented here offers a new approach to the calculation of the distribution of deaths for areas where mortality data are either scarce or unavailable.

\section{Background}

As a part of the Global Burden of Disease 2000 (GBD 2000) project, the present study aims at estimating the total global and regional cancer mortality and incidence based on its detailed analysis of all-cause levels and cause of death distributions for 191 Member States of the World Health Organization (WHO) [1]. GBD 2000 requires ageand sex- specific incidence, duration and mortality as a 
minimum input to estimate burden of each disease sequela by a composite measure of mortality and morbidity (i.e., disability-adjusted life years: DALYs).

Attempts have been made to quantify the global burden of cancer, and estimate site-specific cancer mortality and morbidity [2-6]. Such studies have repeatedly suggested that incidence and mortality from cancer are continuously increasing in many parts of the world. Despite an increasing trend of cancer incidence and mortality, data on survival and prognosis of incident cases from populationbased cancer registries are limited in majority of developing countries. One of the most credible sources of information is available from the International Agency for Research on Cancer (IARC), which has been coordinating and implementing the cancer registries in such regions [7].

While vital registration of causes of death and national cancer registries are perhaps the best source of data on cancer mortality, mortality data are still scarce, poor or even unavailable for some regions of the world. Innovative methods will thus continue to be needed to exploit available data. Estimating mortality from morbidity and, especially, morbidity from mortality was a common practice in the 70's and 80's [8,9]. More recently, the continuos effort made by IARC has lead to the Globocan 2000 estimates which has also used information on incidence and survival to estimate cancer death for the year 2000 from various sources including cancer registries $[2,6]$. Still others have made use of vital statistics and cancer incidence data to predict the number of new cancer cases and deaths for the US in the subsequent year [10].

On the basis of available published information on age-, sex-, and site-specific cancer incidence and survival, we developed an algorithm to estimate region-specific overall cancer mortality, and site-specific survival, death distributions and incidence for the year 2000. This paper presents the first of the two consecutive reports which present the detailed methods and results of GBD 2000 estimates for mortality and incidence of cancer by site.

The particular feature of the GBD 2000 study is that the number of deaths by age and sex in each region provides an essential envelope which constrains individual disease and injury estimates of deaths and that competing claims for the magnitude of deaths from various causes must be reconciled within this envelope [1]. Given the regional cancer mortality envelope by age and sex, the estimates of site-specific distributions of cancer mortality are necessary to disagreggate the estimated total cancer deaths by age and sex for each region.
For geographic disaggregation of the GBD 2000, the six WHO regions of the world have been further divided into 14 sub regions, based on levels of child (under five years) and adult (15-59 years) mortality for WHO Member States [1]. Five mortality strata were defined in terms of quintiles of the distribution of child and adult mortality (both sexes combined). Adult mortality was regressed on child mortality and the regression line used to divide countries with high child mortality into high adult mortality (stratum D) and very high adult mortality (stratum E). Stratum E includes the countries in sub-Saharan Africa where HIV/AIDS has had a very substantial impact.

When these mortality strata are applied to the six WHO regions, they produce 14 mortality subregions. For the purposes of burden of disease epidemiological analyses, 2 of these regions were further subdivided: EurB into EurB1 and EurB2 - the latter including the central Asian states; and WprB into WprB1 (mainly China), WprB2 (South East Asian countries) and WprB3 (Pacific Islands). Additionally, some Member States have been reclassified into subregions with similar epidemiological/geographic/ethnic patterns in order to maximise the epidemiological homogeneity of the subregions for the purposes of epidemiological analysis. The resulting 17 epidemiological subregions are listed in Table 1.

The approaches to estimating mortality distributions were different depending on the availability and quality of data on detailed causes of death. Direct estimates of the sitespecific distributions of cancer mortality were possible for the regions where established vital registration records with high coverage and coding practice based on the International Statistical Classification of Diseases and Related Health Problems (ICD) are available, including countries in the A sub regions (AmrA, EurA and WprA) and countries in AmrB, EurB1, EurB2 and EurC [1]. For the other regions of the world (AfrD, AfrE, AmrD, EmrB, EmrD, SearB, SearD, WprB1, WprB2 and WprB3), we developed a site-specific model for relative interval survival adjusted for each region and applied it to the regional incidence estimated to calculate the mortality distribution by site for the year 2000. This model can also be used to estimate survival at different ages and average duration of cancer by site. In this paper, we present a detailed model as a key input to estimate the distribution of cancer deaths by site model for the regions where few data are available.

\section{Material and Methods Data sources}

Relative interval survival based on the US data

The primary data sources used to develop the cancer survival model were the National Cancer Institute Surveillance, Epidemiology, and End Results (SEER) statistical program (SEER*Stat version 4.2). The SEER program is 
Table I: Global Burden of Disease 2000 (GBD 2000) project: regions and sub regions

\begin{tabular}{|c|c|c|c|}
\hline WHO region & Mortality stratum & Sub region & WHO Member States \\
\hline AFRO & $\mathrm{D}$ & AfrD & $\begin{array}{l}\text { Algeria, Angola, Benin, Burkina Faso, Cameroon, Cape Verde, Chad, Comoros, } \\
\text { Equatorial Guinea, Gabon, Gambia, Ghana, Guinea, Guinea-Bissau, Liberia, } \\
\text { Madagascar, Mali, Mauritania, Mauritius, Niger, Nigeria, Sao Tome And Princ- } \\
\text { ipe, Senegal, Seychelles, Sierra Leone, Togo, Djibouti, Somalia, Sudan }\end{array}$ \\
\hline AFRO & $\mathrm{E}$ & AfrE & $\begin{array}{l}\text { Botswana, Burundi, Central African Republic, Congo, Côte d'Ivoire, Demo- } \\
\text { cratic Republic Of The Congo, Eritrea, Ethiopia, Kenya, Lesotho, Malawi, } \\
\text { Mozambique, Namibia, Rwanda, South Africa, Swaziland, Uganda, United } \\
\text { Republic of Tanzania, Zambia, Zimbabwe }\end{array}$ \\
\hline AMRO & A & AmrA & Canada, United States Of America \\
\hline \multirow[t]{2}{*}{ AMRO } & B & AmrB & $\begin{array}{l}\text { Antigua And Barbuda, Argentina, Bahamas, Barbados, Belize, Brazil, Chile, } \\
\text { Colombia, Costa Rica, Dominica, Dominican Republic, El Salvador, Grenada, } \\
\text { Guyana, Honduras, Jamaica, Mexico, Panama, Paraguay, Saint Kitts And Nevis, } \\
\text { Saint Lucia, Saint Vincent And The Grenadines, Suriname, Trinidad And } \\
\text { Tobago, Uruguay, Venezuela }\end{array}$ \\
\hline & & & Cuba \\
\hline AMRO & $\mathrm{D}$ & AmrD & Bolivia, Ecuador, Guatemala, Haiti, Nicaragua, Peru \\
\hline EMRO & B & EmrB & $\begin{array}{l}\text { Bahrain, Cyprus, Iran (Islamic Republic Of), Jordan, Kuwait, Lebanon, Libyan } \\
\text { Arab Jamahiriya, Oman, Qatar, Saudi Arabia, Syrian Arab Republic, Tunisia, } \\
\text { United Arab Emirates }\end{array}$ \\
\hline EMRO & $\mathrm{D}$ & EmrD & Egypt, Iraq, Morocco, Yemen \\
\hline EURO & A & EurA & $\begin{array}{l}\text { Andorra, Austria, Belgium, Croatia, Czech Republic, Denmark, Finland, France, } \\
\text { Germany, Greece, Iceland, Ireland, Israel, Italy, Luxembourg, Malta, Monaco, } \\
\text { Netherlands, Norway, Portugal, San Marino, Slovenia, Spain, Sweden, Switzer- } \\
\text { land, United Kingdom }\end{array}$ \\
\hline EURO & BI & EurBI & $\begin{array}{l}\text { Albania, Bosnia And Herzegovina, Bulgaria, Georgia, Poland, Romania, Slovakia, } \\
\text { The Former Yugoslav Republic Of Macedonia, Turkey, Yugoslavia }\end{array}$ \\
\hline EURO & $\mathrm{B} 2$ & EurB2 & Armenia, Azerbaijan, Kyrgyzstan, Tajikistan, Turkmenistan, Uzbekistan \\
\hline EURO & C & EurC & Republic of Moldova, Russian Federation, Ukraine \\
\hline SEARO & B & SearB & $\begin{array}{l}\text { Indonesia, Sri Lanka, Thailand Malaysia, Philippines Brunei Darussalam, Singa- } \\
\text { pore }\end{array}$ \\
\hline SEARO & $\mathrm{D}$ & SearD & Bangladesh, Bhutan, India, Maldives, Nepal Afghanistan, Pakistan \\
\hline WPRO & A & WprA & Australia, Japan, New Zealand \\
\hline WPRO & $\mathrm{BI}$ & WprBI & China, Mongolia, Republic Of Korea DPR Korea \\
\hline WPRO & B2 & WprB2 & Cambodia, Lao People's Democratic Republic, Viet Nam Myanmar \\
\hline WPRO & B3 & WprB3 & $\begin{array}{l}\text { Cook Islands, Fiji, Kiribati, Marshall Islands, Micronesia (Federated States Of), } \\
\text { Nauru, Niue, Palau, Papua New Guinea, Samoa, Solomon Islands, Tonga, } \\
\text { Tuvalu, Vanuatu }\end{array}$ \\
\hline
\end{tabular}

considered as the standard for quality among cancer registries around the world, being the most authoritative source of information on cancer incidence and survival in the United States [11], RIS was directly obtained from the SEER database (1973-1997 Public-Use Data) within SE$\mathrm{ER}^{*}$ Stat for every age group, sex, and cancer site. Cancer sites for which survival was calculated were: mouth and pharynx (ICD-10 C00-C14), oesophagus (C15), stomach (C16), colon and rectum (C18-C21), liver (C22), pancreas (C25), trachea, bronchus and lung (C33-C34), melanoma of the skin (C43), female breast (C50), cervix uteri (C53), corpus uteri (C54-55), ovary (C56), prostate (C61), bladder (C67), lymphomas and multiple myeloma (C81-C90, C96), leukaemia (C91-C95), and other malignant neoplasms (balance of ICD-10 C00-C97).

\section{Incidence data}

We initially used the Globocan 2000 estimates of the international Agency for Research on Cancer (IARC) to apply the survival model for a region [6], assuming that incidence rates to be constant over the years. We then estimated the region-specific number of new cases for 1986 to 2000, by applying these age-specific incidence rates to the annual population. We carefully examined the methods used to estimate country-specific incidence data in Globocan 2000, to ensure that for all the regions where we required incidence estimates, the Globocan estimates were based on cancer registry incidence data, and not modelled from mortality data using assumptions about survival (which would then result in circularity in our mortality estimation process for regions without good mortality data by cancer site). 
Table 2: Estimated relative probability of death after I year $\left(I-R I S_{I}\right)$

\begin{tabular}{lll}
\hline Site & Males & Females \\
\hline Mouth and pharynx & 0.202 & 0.180 \\
Oesophagus & 0.660 & 0.635 \\
Stomach & 0.574 & 0.558 \\
Colon and rectum & 0.207 & 0.223 \\
Trachea, bronchus and lung & 0.831 & 0.769 \\
Pancreas & 0.828 & 0.816 \\
Lung & 0.631 & 0.568 \\
Melanoma of the skin & 0.052 & 0.029 \\
Breast & & 0.039 \\
Cervix & & 0.126 \\
Uterus & & 0.073 \\
Ovary & & 0.289 \\
Prostate & 0.037 & \\
Bladder & 0.091 & 0.153 \\
Non-Hodgkin lymphoma & 0.297 & 0.253 \\
Hodgkin lymphoma & 0.108 & 0.089 \\
Multiple myeloma & 0.286 & 0.297 \\
Leukemia & 0.360 & 0.376 \\
Others & 0.348 & 0.386 \\
\hline
\end{tabular}

Globocan 2000 estimates of cancer incidence by site for countries differ from those required for the GBD 2000 in two major respects: 1) Globocan 2000 estimates include Kaposi's sarcoma and non-Hodgkin lymphomas (NHL) caused by HIV/AIDS. The GBD 2000 includes these cases among AIDS sequela and their burden is included with the HIV/AIDS burden [12-14] and 2) Globocan 2000 estimates include cancers of unknown primary with cancers of other specified sites. The GBD 2000 attributes these illdefined cancers back to specific sites as described above. Accordingly Globocan 2000 incidence estimates by age, sex, site and country were adjusted for these differences. Firstly, unpublished data on the incidence of Kaposi's sarcoma for countries in Africa were provided by IARC and used to adjust incidence of other cancers to remove incidence of Kaposi's sarcoma. Secondly, relative risks of HNL from HIV [15-18] were estimated and, together with the UNAIDS prevalence estimates of HIV in each country of the African region, NHL attributable to HIV was also removed. Thirdly, incidence estimates for cancers of unknown primary site were redistributed among specific sites using the GBD 2000 algorithm [1]. The proportion of the others category (balance of all but skin cancers) in the Globocan 2000 corresponding to unknown primary sites was estimated from published data on the distribution of cancer incidence by site which included unknown primary as a specific category [19-27].

After adjusting the Globocan 2000 incidence estimates for each country as described above, these estimates were summed for the countries in each GBD 2000 region, re- sulting in estimated incidence distributions by site, age and sex for each region. Finally, the GBD 2000 uses the latest population estimates for the Member States of the World Health Organization prepared by the United Nations Population Division [28]. In order to obtain incidence from 1986 to 2000, we estimated the age-specific population by sex for each of these years, using growth rates also from the United Nation's data.

\section{Multiplicative model of relative interval survival}

In order to estimate cancer death distribution for regions where little cancer mortality data is available (AfrD, AfrE, AmrD, EmrB, EmrD, SearB, SearD, WprB1, WprB2 and WprB3 sub regions), we developed an age-period-cohort multiplicative model for the relative interval survival (RIS) for each site. To incorporate all three time dimensions, we have taken into account the relative survival for every 5-year age group from 0 up to $85+$ years of age, and for calendar year for 15 years (1981 to 1995), and for time since cancer diagnosis (survival time for cohorts) from 1up to 15-year survival. After obtaining the time-specific survival data, we have then further indexed all the age, time, and calendar year survival information to the first year interval survival for each sex, and cancer site. The first year of survival was chosen because, for most if not all cancer sites, it is the most critical year concerning cancer survival experience. After the first year of survival, the relative survival curve usually increases and then flattens smoothly. Indexing was done by dividing each of the time-specific RIS by the survival at 1 -year interval. 
Table 3: Estimated age parameters $\left(A_{\alpha}\right)$ by cancer site, age and sex

\begin{tabular}{|c|c|c|c|c|c|c|c|c|c|c|c|c|}
\hline \multirow[b]{2}{*}{ Age } & \multicolumn{2}{|c|}{ Oral } & \multicolumn{2}{|c|}{ Oesophagus } & \multicolumn{2}{|c|}{ Stomach } & \multicolumn{2}{|c|}{ Colon and rectum } & \multicolumn{2}{|c|}{ Liver } & \multicolumn{2}{|c|}{ Pancreas } \\
\hline & Male & Female & Male & Female & Male & Female & Male & Female & Male & Female & Male & Female \\
\hline $0-4$ & 0.870 & 1.093 & 0.957 & 0.944 & 0.864 & 0.814 & 1.169 & 0.288 & 0.330 & 0.388 & 0.824 & 0.408 \\
\hline $5-9$ & 0.429 & 0.222 & 0.957 & 0.944 & 0.864 & 0.814 & 1.169 & 0.288 & 0.430 & 0.600 & 0.824 & 0.408 \\
\hline $10-14$ & 0.216 & 0.258 & 0.957 & 0.944 & 0.864 & 0.814 & 1.169 & 0.288 & 0.527 & 0.315 & 0.824 & 0.613 \\
\hline $15-19$ & 0.185 & 0.200 & 0.957 & 0.944 & 0.864 & 0.814 & 1.169 & 0.688 & 0.225 & 0.585 & 0.824 & 0.204 \\
\hline $20-24$ & 0.337 & 0.099 & 0.957 & 0.944 & 0.864 & 0.895 & 1.169 & 0.467 & 0.580 & 0.638 & 0.824 & 0.204 \\
\hline $25-29$ & 0.710 & 0.177 & 0.957 & 0.944 & 0.864 & 0.888 & 1.169 & 0.820 & 0.818 & 0.689 & 0.824 & 0.531 \\
\hline $30-34$ & 0.913 & 0.314 & 0.957 & 0.944 & 0.864 & 0.685 & 1.169 & 0.590 & 0.949 & 0.773 & 0.824 & 0.497 \\
\hline $35-39$ & $0.76 \mathrm{I}$ & 0.436 & 0.957 & 0.888 & 0.864 & 0.811 & 0.966 & 0.700 & 0.960 & 0.752 & 0.893 & 0.712 \\
\hline $40-44$ & 0.818 & 0.526 & 0.957 & 0.985 & 0.864 & 0.746 & 0.765 & 0.739 & 1.033 & 0.780 & 0.907 & 0.745 \\
\hline $45-49$ & 0.883 & 0.631 & 0.965 & 0.977 & 0.931 & 0.791 & 0.787 & 0.687 & 0.974 & 0.819 & 0.927 & 0.902 \\
\hline $50-54$ & 0.908 & 0.894 & 0.969 & 1.036 & 0.899 & 0.851 & 0.784 & 0.671 & 0.980 & 0.969 & 0.936 & 0.922 \\
\hline $55-59$ & 0.936 & 0.939 & 0.948 & 0.996 & 0.877 & 0.816 & 0.797 & 0.739 & 1.010 & 0.962 & 0.977 & 0.952 \\
\hline $60-64$ & 1.017 & 0.884 & 0.967 & 0.959 & 0.940 & 0.863 & 0.812 & 0.749 & 1.023 & 0.998 & 0.986 & 0.970 \\
\hline $65-69$ & 1.048 & 1.086 & 1.029 & 0.949 & 0.972 & 0.923 & 0.861 & 0.857 & 1.010 & 1.025 & 1.015 & 0.989 \\
\hline $70-74$ & 1.145 & 1.103 & 1.038 & 0.975 & 0.990 & 0.982 & 0.979 & 0.898 & 1.051 & 1.034 & 1.016 & 1.020 \\
\hline $75-79$ & 1.141 & 1.304 & 1.063 & 0.969 & 1.082 & 1.055 & 1.134 & 1.069 & 1.032 & 1.082 & 1.016 & 1.033 \\
\hline $80-84$ & 1.220 & 1.354 & 1.096 & 1.066 & 1.169 & 1.121 & 1.368 & 1.275 & 1.070 & 1.126 & $1.06 \mathrm{I}$ & 1.058 \\
\hline \multirow[t]{2}{*}{$85+$} & 1.358 & 1.993 & 1.152 & 1.210 & 1.259 & 1.279 & 1.793 & 1.619 & 1.039 & 1.126 & 1.082 & 1.084 \\
\hline & \multicolumn{2}{|c|}{ Lung } & \multicolumn{2}{|c|}{ Bladder } & \multicolumn{2}{|c|}{$\begin{array}{l}\text { Non-Hodgkin } \\
\text { lymphoma }\end{array}$} & \multicolumn{2}{|c|}{$\begin{array}{l}\text { Hodgkin lym- } \\
\text { phoma }\end{array}$} & \multicolumn{2}{|c|}{$\begin{array}{l}\text { Multiple mye- } \\
\text { loma }\end{array}$} & \multicolumn{2}{|c|}{ Leukaemia } \\
\hline Age & Male & Female & Male & Female & Male & Female & Male & Female & Male & Female & Male & Female \\
\hline $0-4$ & 0.711 & 0.849 & 0.107 & 0.141 & 0.824 & 0.823 & 0.476 & 0.000 & 1.000 & 1.000 & 0.356 & 0.354 \\
\hline $5-9$ & 0.711 & 0.849 & 0.107 & $0.14 \mid$ & 0.716 & 0.502 & 0.304 & 0.972 & 1.000 & 1.000 & 0.280 & 0.224 \\
\hline $10-14$ & 0.711 & 0.849 & 0.107 & 0.141 & 0.791 & 0.664 & 0.226 & 0.493 & 1.000 & 1.000 & 0.483 & 0.525 \\
\hline $15-19$ & 0.711 & 0.849 & 0.107 & 0.141 & 0.850 & 0.859 & 0.159 & 0.191 & 1.000 & 1.000 & 0.703 & 0.684 \\
\hline $20-24$ & 0.711 & 0.849 & 0.107 & 0.141 & 0.953 & 0.767 & 0.303 & 0.204 & 1.000 & 1.000 & 0.865 & 0.815 \\
\hline $25-29$ & 0.711 & 0.849 & 0.107 & 0.159 & $1.26 \mathrm{I}$ & 0.673 & 0.280 & 0.161 & 0.431 & 0.318 & 0.883 & 0.936 \\
\hline $30-34$ & 0.926 & 0.849 & 0.182 & 0.393 & 1.381 & 0.677 & 0.507 & 0.259 & 0.670 & 0.619 & 0.814 & 0.796 \\
\hline $35-39$ & 0.939 & 0.849 & 0.157 & 0.533 & 1.320 & 0.565 & 0.492 & 0.422 & 0.485 & 0.540 & 0.866 & 0.872 \\
\hline $40-44$ & 0.922 & 0.890 & 0.344 & 0.459 & 1.107 & 0.521 & 0.794 & 0.346 & 0.591 & 0.622 & 0.702 & 0.801 \\
\hline $45-49$ & 0.909 & 0.891 & 0.443 & 0.452 & 0.872 & 0.526 & 1.145 & 0.744 & 0.556 & 0.525 & 0.770 & 0.882 \\
\hline $50-54$ & 0.920 & 0.891 & 0.459 & 0.405 & 0.715 & 0.576 & 1.262 & 1.084 & 0.700 & 0.725 & 0.780 & 0.830 \\
\hline $55-59$ & 0.932 & 0.918 & 0.550 & 0.522 & 0.713 & 0.630 & 1.401 & 1.683 & 0.684 & 0.669 & 0.811 & 0.829 \\
\hline $60-64$ & 0.954 & 0.937 & 0.756 & 0.637 & 0.809 & 0.760 & 2.194 & 2.317 & 0.800 & 0.785 & 0.899 & 0.880 \\
\hline $65-69$ & 0.986 & 0.979 & 0.751 & 0.764 & 0.860 & 0.877 & 2.581 & 3.020 & 0.898 & 0.762 & 0.991 & 0.959 \\
\hline 70-74 & 1.039 & 1.038 & 1.069 & 0.878 & 1.003 & 1.058 & 3.753 & 3.912 & 1.139 & 0.942 & 1.192 & 1.068 \\
\hline $75-79$ & 1.090 & 1.038 & 1.305 & 1.199 & 1.251 & 1.428 & 4.263 & 4.686 & 1.231 & 1.196 & 1.404 & 1.185 \\
\hline $80-84$ & 1.169 & 1.038 & 1.740 & 1.520 & 1.531 & 1.654 & 4.979 & 4.303 & 1.535 & 1.451 & 1.501 & 1.337 \\
\hline \multirow[t]{2}{*}{$85+$} & 1.219 & 1.038 & 2.453 & 1.956 & 1.863 & 2.105 & 5.372 & 6.393 & 1.828 & 1.743 & 1.563 & 1.535 \\
\hline & \multicolumn{2}{|c|}{ Melanoma } & \multicolumn{2}{|c|}{ Miscellaneous } & Breast & Cervix & Uterus & Ovary & $\begin{array}{l}\text { Pros- } \\
\text { tate }\end{array}$ & & & \\
\hline Age & Male & Female & Male & Female & Female & Female & Female & Female & Male & & & \\
\hline $0-4$ & 1.000 & 3.573 & 0.514 & 0.430 & 0.874 & 0.574 & 0.322 & 0.247 & 0.548 & & & \\
\hline $5-9$ & 1.000 & 1.000 & 0.444 & 0.405 & 0.874 & 0.574 & 0.322 & 0.247 & 0.548 & & & \\
\hline $10-14$ & 0.324 & 0.706 & 0.395 & 0.299 & 0.874 & 0.574 & 0.322 & 0.247 & 0.548 & & & \\
\hline $15-19$ & 0.959 & 0.937 & 0.377 & 0.222 & 0.874 & 0.574 & 0.322 & 0.202 & 0.548 & & & \\
\hline $20-24$ & 0.670 & 0.531 & 0.279 & 0.147 & 0.874 & 0.425 & 0.322 & $0.24 I$ & 0.548 & & & \\
\hline $25-29$ & 0.764 & 0.455 & 0.229 & 0.154 & 0.679 & 0.329 & 0.553 & 0.173 & 0.548 & & & \\
\hline $30-34$ & 0.564 & 0.493 & 0.261 & 0.207 & 0.733 & 0.406 & 0.382 & 0.236 & 0.548 & & & \\
\hline $35-39$ & 0.902 & 0.542 & 0.375 & 0.270 & 0.651 & 0.457 & 0.353 & 0.336 & 0.548 & & & \\
\hline
\end{tabular}


Table 3: Estimated age parameters $\left(A_{\alpha}\right)$ by cancer site, age and sex (Continued)

\begin{tabular}{llllllllll}
\hline $40-44$ & 0.857 & 0.769 & 0.527 & 0.400 & 0.569 & 0.508 & 0.458 & 0.433 & 0.548 \\
$45-49$ & 0.871 & 0.710 & 0.709 & 0.498 & 0.564 & 0.739 & 0.411 & 0.496 & 0.548 \\
$50-54$ & 0.815 & 1.073 & 0.850 & 0.620 & 0.790 & 0.994 & 0.473 & 0.614 & 0.548 \\
$55-59$ & 1.110 & 0.769 & 0.957 & 0.741 & 0.954 & 1.025 & 0.610 & 0.808 & 0.548 \\
$60-64$ & 1.087 & 1.297 & 1.072 & 0.852 & 0.933 & 1.218 & 0.701 & 0.955 & 0.551 \\
$65-69$ & 1.093 & 1.150 & 1.226 & 0.954 & 1.067 & 1.366 & 0.901 & 1.089 & 0.508 \\
$70-74$ & 0.988 & 1.507 & 1.375 & 1.076 & 1.092 & 1.740 & 1.219 & 1.369 & 0.508 \\
$75-79$ & 1.425 & 2.241 & 1.523 & 1.219 & 1.215 & 2.259 & 1.629 & 1.650 & 1.083 \\
$80-84$ & 1.620 & 1.909 & 1.714 & 1.372 & 1.513 & 2.729 & 2.570 & 1.650 & 1.876 \\
$85+$ & 2.008 & 2.738 & 1.914 & 1.555 & 2.438 & 3.358 & 3.705 & 1.650 & 1.876
\end{tabular}

The specification of relative interval survival $\left(R I S_{\alpha, t, \tau}\right)$ for age $\alpha$, calendar year $t$ across the interval $(\tau-1)$ since diagnosis in years, separately for each cancer site, was of the form:

$R I S_{\alpha, t, \tau}=1-\left(1-R I S_{1}\right) A_{\alpha} T_{t} Y_{\tau}$

where $R I S_{1}$ is the relative interval survival after 1 year for all ages, averaged across the calendar years 1973 to 1997 , $A_{\alpha}$ is the ratio of the relative probability of death after 1 year at age $\alpha$ to the relative probability of death after 1 year for all ages averaged across the calendar years 1973 to $1997\left(A_{\alpha}=\frac{1-R I S_{\alpha, 1973-97}}{1-R I S_{1}}\right), T_{t}$ is the ratio of the relative probability of death after 1 year for all ages in calendar year $t$ to the relative probability of death after 1 year for all ages from 1973 to $1997\left(T_{t}=\frac{1-R I S_{t}}{1-R I S_{1}}\right)$ and $Y_{\tau}$ is the ratio of the relative probability of death after $t$ years for all ages to the relative probability of death after 1 year for all ages from 1973 to $1997\left(Y_{\tau}=\frac{1-R I S_{\tau, 1973-97}}{1-R_{1}}\right)$.

To estimate survival for developing regions where little or no data is available, we replaced $T_{t}$ for the "equivalent" calendar year survival term $T_{r}$ in the equation (1) for each region. $T_{r}$ is the ratio of the relative probability of death after 1 year for all ages in the relevant region to the relative probability of death after 1 year for all ages in the SEER data, averaged across the calendar years 1973 to 1997. In this way, we obtain a new calendar year survival term for the model.

Equivalent period survival terms were estimated for each region by examining the relationship between period survival terms and gross domestic product per capita (measured in international dollars adjusted for purchasing power parity) using the following data: 1) SEER survival data for the USA for the years 1973 to 1997 [11,29]; 2)
Connecticut survival data for the years 1950 and 1958 [30]; 3) survival data for the late 1980s from cancer registries in 5 developing countries [31]; 4) survival data for European countries [32]; 5) specific recent national estimates of cancer survival as published [24,33]. Survivorship functions were estimated to derive regional relative survival from registry data by fitting a Weibull distribution function. To allow for a proportion who are cured and never die from the cancer, we modify the Weibull model as follows:

$\mathrm{S}(t)=k+(1-k) \exp \left(-(\lambda t)^{\gamma}\right)$

where $k$ is the proportion who never die from the cancer, $\lambda$ is the location parameter $(1 / \lambda$ is the time at which $50 \%$ of those will die have died) and $\gamma$ is the shape parameter. The mean survival time for those who die $\left(\frac{T}{T}\right)$ is given by

$\bar{T}=\frac{1}{\lambda} \Gamma\left(\frac{\gamma+1}{\gamma}\right)(3)$

where $\Gamma$ denotes the gamma distribution. The analysis of survival data in developed regions suggested that the 10year relative survival can be used as an estimate of the proportion who never die from the cancer. This is particularly useful when relative survival point estimates fluctuate significantly and the plausible exact solutions did not obtained as in some developing regions. To assess the goodness-of-fit of the survival curve, we compared fitted 5 -year survival with the observed survival and ensured the good fits in all cases.

There are substantial variations in relative interval survival (all ages) among countries; these variations are even larger, and fluctuate substantially with age, when the age-sex specific survival estimates are examined. There is also a possibility of correlation among the observations within a same region. Thus we employed both liner and non-linear feasible generalised least squares (FGLS) by maximum likelihood estimation to accommodate with hetero- 
Table 4: Estimated time since diagnosis (cohort) parameters $\left(Y_{\tau}\right)$ by cancer site, year from diagnosis and sex

\begin{tabular}{|c|c|c|c|c|c|c|c|c|c|c|c|c|}
\hline \multirow[b]{2}{*}{ Year } & \multicolumn{2}{|c|}{ Oral } & \multicolumn{2}{|c|}{ Oesophagus } & \multicolumn{2}{|c|}{ Stomach } & \multicolumn{2}{|c|}{$\begin{array}{l}\text { Colon and rec- } \\
\text { tum }\end{array}$} & \multicolumn{2}{|c|}{ Liver } & \multicolumn{2}{|c|}{ Pancreas } \\
\hline & Male & Female & Male & Female & Male & Female & Male & Female & Male & Female & Male & Female \\
\hline I & 1.000 & 1.000 & 1.000 & 1.000 & 1.000 & 1.000 & 1.000 & 1.000 & 1.000 & 1.000 & 1.000 & 1.000 \\
\hline 2 & 0.877 & 0.855 & 0.752 & 0.753 & 0.640 & 0.564 & 0.609 & 0.572 & 0.591 & 0.542 & 0.721 & 0.720 \\
\hline 3 & 0.542 & 0.472 & 0.462 & 0.483 & 0.387 & 0.349 & 0.443 & 0.388 & 0.368 & 0.352 & 0.434 & 0.430 \\
\hline 4 & 0.377 & 0.329 & 0.313 & 0.251 & 0.251 & 0.186 & 0.345 & 0.267 & 0.265 & 0.219 & 0.257 & 0.226 \\
\hline 5 & 0.300 & 0.268 & 0.214 & 0.216 & 0.173 & 0.117 & 0.240 & 0.189 & 0.268 & 0.174 & 0.156 & 0.170 \\
\hline 6 & 0.235 & 0.282 & 0.175 & 0.181 & 0.109 & 0.099 & 0.185 & 0.134 & 0.116 & 0.104 & 0.150 & 0.108 \\
\hline 7 & 0.241 & 0.268 & 0.173 & 0.109 & 0.087 & 0.065 & 0.144 & 0.114 & 0.118 & 0.083 & 0.116 & 0.092 \\
\hline 8 & 0.217 & 0.224 & 0.145 & 0.168 & 0.063 & 0.084 & 0.094 & 0.085 & 0.073 & 0.093 & 0.100 & 0.104 \\
\hline 9 & 0.211 & 0.241 & 0.095 & 0.168 & 0.035 & 0.068 & 0.079 & 0.068 & 0.041 & 0.075 & 0.062 & 0.078 \\
\hline 10 & 0.236 & 0.213 & 0.084 & 0.138 & 0.048 & 0.046 & 0.068 & 0.059 & 0.000 & 0.049 & 0.085 & 0.051 \\
\hline II & 0.219 & 0.197 & 0.057 & 0.145 & 0.016 & $0.04 I$ & 0.024 & 0.033 & 0.000 & 0.045 & 0.047 & 0.048 \\
\hline 12 & 0.217 & 0.180 & 0.030 & 0.142 & 0.000 & 0.031 & 0.000 & 0.014 & 0.000 & 0.034 & 0.029 & 0.036 \\
\hline 13 & 0.214 & 0.164 & 0.004 & 0.139 & 0.000 & 0.021 & 0.000 & 0.000 & 0.000 & 0.022 & 0.010 & 0.023 \\
\hline 14 & 0.211 & 0.147 & 0.000 & 0.137 & 0.000 & 0.010 & 0.000 & 0.000 & 0.000 & 0.010 & 0.000 & 0.010 \\
\hline \multirow[t]{2}{*}{15} & 0.208 & 0.131 & 0.000 & 0.134 & 0.000 & 0.000 & 0.000 & 0.000 & 0.000 & 0.000 & 0.000 & 0.000 \\
\hline & \multicolumn{2}{|c|}{ Lung } & \multicolumn{2}{|c|}{ Bladder } & \multicolumn{2}{|c|}{$\begin{array}{l}\text { Non-Hodgkin } \\
\text { lymphoma }\end{array}$} & \multicolumn{2}{|c|}{$\begin{array}{l}\text { Hodgkin lym- } \\
\text { phoma }\end{array}$} & \multicolumn{2}{|c|}{$\begin{array}{l}\text { Multiple mye- } \\
\text { loma }\end{array}$} & \multicolumn{2}{|c|}{ Leukaemia } \\
\hline Year & Male & Female & Male & Female & Male & Female & Male & Female & Male & Female & Male & Female \\
\hline I & 1.000 & 1.000 & 1.000 & 1.000 & 1.000 & 1.000 & 1.000 & 1.000 & 1.000 & 1.000 & 1.000 & 1.000 \\
\hline 2 & 0.683 & 0.693 & 0.621 & 0.478 & 0.442 & 0.480 & 0.589 & 0.654 & 0.725 & 0.755 & 0.466 & 0.438 \\
\hline 3 & 0.402 & 0.384 & 0.391 & 0.267 & 0.277 & 0.289 & 0.411 & 0.417 & 0.792 & 0.711 & 0.334 & 0.280 \\
\hline 4 & 0.254 & 0.235 & 0.313 & 0.191 & 0.235 & $0.24 I$ & 0.384 & 0.290 & 0.728 & 0.692 & 0.282 & 0.259 \\
\hline 5 & 0.181 & 0.186 & 0.277 & 0.141 & 0.220 & 0.233 & 0.304 & 0.224 & 0.764 & 0.732 & 0.251 & 0.236 \\
\hline 6 & 0.145 & 0.144 & 0.251 & $0.14 I$ & 0.195 & 0.233 & 0.301 & 0.290 & 0.689 & 0.740 & 0.225 & 0.206 \\
\hline 7 & 0.123 & 0.134 & 0.249 & 0.131 & 0.188 & 0.222 & 0.307 & 0.263 & 0.643 & 0.727 & 0.225 & 0.189 \\
\hline 8 & 0.120 & 0.117 & 0.231 & 0.108 & 0.166 & 0.217 & 0.252 & 0.219 & 0.601 & 0.579 & 0.215 & 0.172 \\
\hline 9 & 0.113 & 0.116 & 0.252 & 0.139 & 0.163 & 0.183 & 0.242 & 0.191 & 0.596 & 0.570 & 0.194 & 0.165 \\
\hline 10 & 0.113 & 0.114 & 0.257 & 0.165 & 0.145 & 0.171 & 0.198 & 0.188 & 0.510 & 0.453 & 0.168 & 0.153 \\
\hline 11 & 0.101 & 0.102 & 0.253 & 0.154 & 0.137 & 0.177 & 0.179 & 0.124 & 0.537 & 0.466 & 0.162 & 0.139 \\
\hline 12 & 0.093 & 0.094 & 0.255 & 0.160 & 0.128 & 0.170 & 0.161 & 0.102 & 0.519 & 0.430 & 0.147 & 0.126 \\
\hline 13 & 0.085 & 0.087 & 0.256 & 0.165 & 0.119 & 0.164 & 0.144 & 0.082 & 0.501 & 0.397 & 0.133 & 0.113 \\
\hline 14 & 0.078 & 0.079 & 0.258 & 0.171 & 0.112 & 0.157 & 0.128 & 0.064 & 0.485 & 0.367 & 0.118 & 0.100 \\
\hline \multirow[t]{2}{*}{15} & 0.070 & 0.071 & 0.260 & 0.177 & 0.104 & 0.152 & 0.114 & 0.046 & $0.47 I$ & 0.338 & 0.104 & 0.088 \\
\hline & \multicolumn{2}{|c|}{ Melanoma } & \multicolumn{2}{|c|}{ Miscellaneous } & Breast & Cervix & Uterus & Ovary & $\begin{array}{c}\text { Pros- } \\
\text { tate }\end{array}$ & & & \\
\hline Year & Male & Female & Male & Female & Female & Female & Female & Female & Male & & & \\
\hline I & 1.000 & 1.000 & 1.000 & 1.000 & 1.000 & 1.000 & 1.000 & 1.000 & 1.000 & & & \\
\hline 2 & 0.967 & 0.972 & 0.423 & 0.361 & 1.205 & 0.869 & 0.656 & 0.726 & 1.108 & & & \\
\hline 3 & 0.801 & 0.962 & 0.215 & 0.194 & 1.297 & 0.507 & 0.418 & 0.461 & 1.142 & & & \\
\hline 4 & 0.622 & $0.74 I$ & 0.152 & 0.127 & I.I54 & 0.337 & 0.233 & 0.315 & 1.065 & & & \\
\hline 5 & 0.459 & 0.514 & 0.109 & 0.091 & 1.051 & 0.232 & 0.141 & 0.232 & 1.051 & & & \\
\hline 6 & 0.392 & 0.531 & 0.097 & 0.079 & 0.926 & 0.196 & 0.118 & 0.169 & 1.038 & & & \\
\hline
\end{tabular}


Table 4: Estimated time since diagnosis (cohort) parameters $\left(Y_{\tau}\right)$ by cancer site, year from diagnosis and sex (Continued)

\begin{tabular}{lllllllllll}
\hline 7 & 0.280 & 0.339 & 0.082 & 0.067 & 0.879 & 0.162 & 0.070 & 0.110 & 1.113 & \\
8 & 0.239 & 0.329 & 0.070 & 0.056 & 0.744 & 0.146 & 0.066 & 0.113 & 1.099 & \\
9 & 0.220 & 0.248 & 0.069 & 0.052 & 0.756 & 0.095 & 0.048 & 0.089 & 1.022 & 1.013 \\
10 & 0.085 & 0.217 & 0.066 & 0.050 & 0.705 & 0.119 & 0.038 & 0.061 & 0.038 & 1.015 \\
11 & 0.101 & 0.117 & 0.054 & 0.039 & 0.633 & 0.078 & 0.014 & 0.038 & \\
12 & 0.026 & 0.045 & 0.047 & 0.032 & 0.576 & 0.056 & 0.000 & 0.014 & 1.001 & 0.987 \\
13 & 0.000 & 0.000 & 0.039 & 0.025 & 0.520 & 0.034 & 0.000 & 0.000 & 0.973 \\
14 & 0.000 & 0.000 & 0.032 & 0.017 & 0.464 & 0.012 & 0.000 & 0.000 & 0.959 \\
15 & 0.000 & 0.000 & 0.024 & 0.010 & 0.407 & 0.000 & 0.000 & 0.000 & 0.900 \\
\hline
\end{tabular}

scedasticity and correlation among the observations, and chose the best fit model for each site [34]. We did not include region fixed-effects since the data are not available for all sub regions.

\section{Model estimation of cancer death distribution}

For the estimation of the number of deaths and cancer death distribution by site, we needed to estimate the number of individuals who survived up to 2000 by age and time of survival as well as their corresponding probability of death during this year. The number of surviving individuals at age $\alpha$ in 2000 was calculated by multiplying incidence at age $\alpha$ in year $(2000-\tau)$ by the observed interval survival for $\tau$ years since diagnosis for individuals aged $\alpha$ in $2000\left(\mathrm{OIS}_{\alpha, \tau}\right)$, and summing over $\tau$. To estimate OI$\mathrm{S}_{\alpha, \tau}$, we first calculated the relative cumulative survival $\left(\mathrm{RCS}_{\alpha, \tau}\right)$ for every single age and year of survival for 2000, by multiplying RIS ${ }_{\alpha, \tau}$ over the years of survival. In a standard life table format, OIS ${ }_{\alpha, \tau}$ is written of the from:

$O I S_{\alpha, \tau}=R C S_{\alpha, \tau}\left(l_{\alpha+1} / l_{\alpha-\tau+1}\right)=\exp \left(-\left(-\ln \left(R C S_{\alpha, \tau}\right)+\sum_{x=\alpha-\tau+1}^{\alpha} h_{x}\right)\right)$

where $l_{x}$ is the number of individuals surviving at exact age $x$ in the life table, $h_{x}=\ln \left(l_{x+1} / l_{x}\right), \alpha$ is age and $\tau$ is time since diagnosis.

The number of individuals $S_{\alpha, \tau}$ who had survived up to 2000 was by multiplying incidence and observed interval survival for the corresponding year of age and survival time:

$S_{\alpha, \tau}=I_{\alpha-\tau, 2000-\tau} O I S_{\alpha, \tau}$

where $I_{\alpha, t}$ is the incidence at age $\alpha$ in calendar year t. For example, the number of individuals who were 7 years of age $(\alpha=7)$ in 2000, and who had survived cancer for 4 years $(\tau=4)$ in 2000 was calculated by multiplying the incidence of cancer for the cohort of individuals who were 3 years of age $(\alpha-\tau=3)$ in $1996(=2000-\tau)$ (year of diag- nosis) by the OIS ${ }_{\alpha, \tau}$ calculated for a 7 year old person who had survived 4 years since cancer diagnosis.

The probability of dying in 2000 due to cancer hazard, for each single age and year of survival, was calculated as follows:

$P_{\alpha, \tau}=\left[1-\exp \left(-\left(-\ln \left(R I S_{\alpha, \tau}\right)+h_{\alpha}\right)\right)\right]\left[-\ln \left(R I S_{\alpha, \tau}\right) /(-\ln (R I S\right.$ $\left.\left.\alpha, \tau)+h_{\alpha}\right)\right]$

For each site, the number of deaths in 2000, among those individuals aged $\alpha$ years and who had survived cancer for $\tau$ years, was estimated by multiplied the number of survivors $S_{\alpha, \tau}$ by the relevant probability of dying in 2000 due to cancer hazard $P_{\alpha, \tau}$. The total cancer deaths of the same site in 2000 at age $\alpha$ years is then estimated by summing over all survival times $\tau$ :

$D_{\alpha}=\sum_{\tau} S_{\alpha, \tau} P_{\alpha, \tau}(7)$

Based on these region-specific adjusted incidence estimates and survival levels, cancer deaths were calculated by equations (3)-(6) for each region by age group and sex to estimate the distribution, but not the magnitude, of cancer by site, sex, and age group.

\section{Validation of the model}

We tested the validity and performance of the proposed survival model in three different ways. Firstly, we compared our estimated RIS $\alpha_{\alpha, t}, \tau$ for $\tau=1$ to 10 years individuals diagnosed with cancer in 1986 with the SEER RIS ${ }_{\alpha, t, \tau}$ for $\tau=1$ to 10 years for the same cohort of individuals. Secondly, we compared the model estimates of cancer mortality distribution with the observed distributions in the regions with good vital records (AmrB, EurA, EurB, EurC and WprA sub regions). AmrA sub region was excluded for the validation purpose since it includes the United States. Finally we compared the cancer death distribution of our model with the Globocan 2000 estimates for the regions where no vital records are available (AfrD, 
Table 5: Estimated period parameters $\left(T_{t}\right)$ for $198 \mathrm{I}-1995$ by cancer site, calendar year, and sex

\begin{tabular}{|c|c|c|c|c|c|c|c|c|c|c|c|c|}
\hline \multirow[b]{2}{*}{ Year } & \multicolumn{2}{|c|}{ Oral } & \multicolumn{2}{|c|}{ Oesophagus } & \multicolumn{2}{|c|}{ Stomach } & \multicolumn{2}{|c|}{$\begin{array}{l}\text { Colon and rec- } \\
\text { tum }\end{array}$} & \multicolumn{2}{|c|}{ Liver } & \multicolumn{2}{|c|}{ Pancreas } \\
\hline & Male & Female & Male & Female & Male & Female & Male & Female & Male & Female & Male & Female \\
\hline 1981 & 0.991 & 1.035 & 1.121 & 1.180 & 1.060 & 1.003 & 0.983 & 1.013 & 1.092 & 1.092 & 1.004 & 1.022 \\
\hline 1982 & 1.019 & 1.048 & 1.054 & 0.971 & 0.949 & 1.066 & 0.986 & 1.017 & 1.031 & 1.036 & 0.998 & 1.014 \\
\hline 1983 & 1.065 & 1.095 & 1.046 & 1.046 & 0.939 & 0.992 & 0.989 & 1.026 & 1.019 & 1.033 & 0.997 & 0.980 \\
\hline 1984 & 0.925 & 1.090 & 0.959 & 0.944 & 1.051 & 0.967 & 0.998 & 0.938 & 0.991 & 1.053 & 1.039 & 0.989 \\
\hline 1985 & 0.895 & 1.053 & 0.975 & 0.957 & 0.993 & 0.994 & 0.904 & 0.949 & 0.974 & 1.000 & 1.018 & 1.022 \\
\hline 1986 & 1.070 & 0.910 & 0.997 & 0.995 & 1.007 & 0.900 & 0.850 & 0.893 & 1.015 & 1.028 & 0.988 & 1.000 \\
\hline 1987 & 0.994 & 0.979 & 0.996 & 0.954 & 1.002 & 0.976 & 0.883 & 0.904 & 0.952 & 0.966 & 0.988 & 0.987 \\
\hline 1988 & 0.954 & 0.887 & 0.998 & 0.925 & 0.940 & 0.918 & 0.914 & 0.917 & 1.009 & 1.030 & 0.976 & 1.008 \\
\hline 1989 & 1.104 & 0.984 & 0.933 & 0.943 & 0.919 & 0.980 & 0.870 & 0.876 & 0.944 & 1.029 & 0.984 & 0.967 \\
\hline 1990 & 1.000 & 0.896 & 0.886 & 1.049 & 0.937 & 0.956 & 0.824 & 0.867 & 0.959 & 0.985 & 0.972 & 0.986 \\
\hline 1991 & 0.991 & 0.959 & 0.880 & 0.893 & 0.998 & 0.932 & 0.810 & 0.824 & 0.969 & 0.944 & 0.962 & 0.974 \\
\hline 1992 & 1.070 & 0.992 & 0.889 & 0.902 & 0.952 & 0.903 & 0.832 & 0.871 & 1.011 & 0.959 & 0.993 & 0.949 \\
\hline 1993 & 0.998 & 0.865 & 0.904 & 1.017 & 0.966 & 0.944 & 0.888 & 0.894 & 0.972 & 0.982 & 0.994 & 0.985 \\
\hline 1994 & 0.842 & 0.965 & 0.936 & 0.938 & 0.935 & 0.966 & 0.833 & 0.875 & 0.933 & 0.914 & 0.964 & 0.983 \\
\hline \multirow[t]{2}{*}{1995} & 0.899 & 0.942 & 0.887 & 0.927 & 0.900 & 0.981 & 0.896 & 0.971 & 0.942 & 0.943 & 0.995 & 0.987 \\
\hline & \multicolumn{2}{|c|}{ Lung } & \multicolumn{2}{|c|}{ Bladder } & \multicolumn{2}{|c|}{$\begin{array}{l}\text { Non-Hodgkin } \\
\text { lymphoma }\end{array}$} & \multicolumn{2}{|c|}{$\begin{array}{l}\text { Hodgkin lym- } \\
\text { phoma }\end{array}$} & \multicolumn{2}{|c|}{$\begin{array}{l}\text { Multiple mye- } \\
\text { loma }\end{array}$} & \multicolumn{2}{|c|}{ Leukaemia } \\
\hline Year & Male & Female & Male & Female & Male & Female & Male & Female & Male & Female & Male & Female \\
\hline 1981 & 1.020 & 1.017 & 0.916 & 1.052 & 0.882 & 0.960 & 0.994 & 1.675 & 0.985 & 1.107 & 1.004 & 0.916 \\
\hline 1982 & 0.994 & 1.000 & 1.179 & 0.775 & 1.033 & 1.069 & 1.240 & 0.888 & 1.008 & 0.837 & 1.042 & 1.043 \\
\hline 1983 & 0.988 & 0.996 & 0.998 & 1.005 & 0.788 & 0.946 & 0.840 & 1.009 & 0.809 & 0.975 & 1.033 & 1.030 \\
\hline 1984 & 0.994 & 1.009 & 1.090 & 0.762 & 0.883 & 0.999 & 0.756 & 0.775 & 1.066 & 1.018 & 0.981 & 0.985 \\
\hline 1985 & 0.997 & 0.972 & 0.972 & 1.039 & 0.949 & 1.021 & 0.834 & 0.947 & 0.914 & 0.989 & 0.962 & 0.963 \\
\hline 1986 & 0.976 & 0.986 & 0.925 & 0.883 & 1.010 & 1.102 & 0.994 & 0.579 & 1.015 & 0.911 & 0.982 & 0.936 \\
\hline 1987 & 0.977 & 1.015 & 0.885 & 0.995 & 1.016 & 0.898 & 0.867 & 0.880 & 0.795 & 0.876 & 0.959 & 1.023 \\
\hline 1988 & 0.980 & 0.995 & 0.851 & 0.859 & 1.043 & 0.967 & 0.854 & 0.978 & 0.866 & 0.930 & 0.905 & 0.937 \\
\hline 1989 & 0.982 & 0.981 & 0.746 & 0.908 & 1.064 & 0.997 & 1.036 & 0.747 & 0.969 & 0.966 & 0.977 & 0.946 \\
\hline 1990 & 0.982 & 0.985 & 0.869 & 1.040 & 1.125 & 0.959 & 0.863 & 1.021 & 0.996 & 0.938 & 0.918 & 0.930 \\
\hline 1991 & 0.968 & 0.971 & 0.918 & 0.907 & 1.115 & 0.991 & 0.634 & 0.811 & 0.782 & 0.880 & 0.930 & 0.959 \\
\hline 1992 & 0.964 & 0.986 & 0.894 & 0.942 & 1.059 & 1.000 & 0.831 & 0.579 & 0.946 & 1.176 & 0.920 & 0.925 \\
\hline 1993 & 0.979 & 0.977 & 0.844 & 0.897 & 1.069 & 0.965 & 0.998 & 0.583 & 1.036 & 0.834 & 0.927 & 0.972 \\
\hline 1994 & 0.975 & 0.990 & 0.844 & 0.935 & 1.091 & 0.987 & 0.590 & 0.787 & 0.892 & 0.965 & 0.927 & 1.018 \\
\hline \multirow[t]{2}{*}{1995} & 0.968 & 0.990 & 0.815 & 0.878 & 1.116 & 1.007 & 0.719 & 0.655 & 0.895 & 0.936 & 0.952 & 1.026 \\
\hline & \multicolumn{2}{|c|}{ Melanoma } & \multicolumn{2}{|c|}{ Miscellaneous } & Breast & Cervix & Uterus & Ovary & $\begin{array}{c}\text { Pros- } \\
\text { tate }\end{array}$ & & & \\
\hline Year & Male & Female & Male & Female & Female & Female & Female & Female & Male & & & \\
\hline 1981 & 1.230 & 1.467 & 0.928 & 1.089 & 1.182 & 1.091 & 1.229 & 1.076 & 1.589 & & & \\
\hline 1982 & 1.332 & 0.765 & 0.921 & 1.060 & 1.131 & 1.020 & 1.160 & 1.036 & 1.556 & & & \\
\hline 1983 & 0.830 & 0.689 & 0.894 & 1.044 & 1.174 & 0.862 & 1.104 & 1.039 & 1.454 & & & \\
\hline 1984 & I.124 & 0.567 & 0.902 & 0.996 & 1.095 & 0.921 & 1.160 & 0.931 & $1.41 \mathrm{I}$ & & & \\
\hline 1985 & 1.014 & 0.979 & 0.855 & 0.994 & 1.056 & 1.041 & 0.932 & 0.972 & 1.301 & & & \\
\hline 1986 & 0.838 & 0.830 & 0.862 & 0.966 & 0.949 & 1.132 & 0.953 & 1.084 & 1.358 & & & \\
\hline
\end{tabular}


Table 5: Estimated period parameters $\left(T_{t}\right)$ for 198I-1995 by cancer site, calendar year, and sex (Continued)

\begin{tabular}{llllllllll}
\hline 1987 & 0.971 & 1.038 & 0.843 & 0.982 & 0.810 & 0.993 & 1.089 & 1.015 & 1.210 \\
1988 & 0.784 & 0.633 & 0.871 & 0.977 & 0.810 & 1.002 & 1.056 & 0.926 & 0.976 \\
1989 & 1.124 & 0.969 & 0.823 & 0.954 & 0.764 & 0.870 & 1.047 & 0.849 & 0.833 \\
1990 & 0.925 & 0.945 & 0.784 & 0.941 & 0.779 & 0.941 & 1.001 & 0.833 & 0.651 \\
1991 & 0.757 & 0.574 & 0.770 & 0.894 & 0.695 & 0.881 & 1.075 & 0.817 & 0.309 \\
1992 & 0.838 & 1.197 & 0.806 & 0.897 & 0.667 & 1.002 & 0.955 & 0.738 & 0.278 \\
1993 & 0.902 & 0.813 & 0.803 & 0.910 & 0.723 & 0.848 & 1.042 & 0.827 & 0.226 \\
1994 & 0.610 & 1.163 & 0.777 & 0.891 & 0.649 & 0.985 & 1.115 & 0.836 & 0.299 \\
1995 & 0.757 & 0.543 & 0.805 & 0.910 & 0.721 & 0.862 & 0.968 & 0.779 & 0.290
\end{tabular}

AfrE, SearB and SearD sub regions) to assess whether our model estimates are comparable to the estimates extrapolated from the actual observed data from the registries. In all cases, non-parametric tests for trends and Pearson's correlation were performed to examine whether the models estimates and observed data are consistent with each other. All statistical analysis was performed by STATA 7.0 (STATA corporation, College Station, TX).

\section{Results}

\section{Parameter estimates}

Relative interval survival (RIS) was directly obtained from the SEER database for every age group, sex, and cancer site The probability of death in the first year $\left(1-\right.$ RIS $\left._{1}\right)$, which is most crucial for the survival of most cancer patients, is shown in Table 2 . The probability of death varied significantly from less than 5\% in cancers of melanoma, breast, uterus, and prostate to over $80 \%$ in pancreas and liver cancers.

Relative interval survival (RIS) was further indexed to the three parameters in the multiplicative cancer survival model by dividing each of the time-specific probability of death $(1-R I S)$ by the probability of death at 1 -year interval $\left(1-R I S_{1}\right)$. Tables 3,4,5 represent the indexed estimates of three parameters by site for every 5-year age group from 0 up to $85+$ years of age, and for calendar year from 1981 to 1995 , and for time since cancer diagnosis from 1- up to 15 -year survival, respectively. While there is considerable variation in the cohort parameters which reflect the prognosis among patients since the time of diagnosis, both age and period parameters are generally consistent across different types of cancer.

Based on the fitted data for each site and sex, and the estimated GDP per capita in international dollars for each region in 2000, $T_{r}$ factors were estimated for each site and sex for each GBD 2000 region. The results are presented in Table 6. An example is shown for breast cancer: knowing that GDP per capita in AfrD was $\$ 1,158$ in 2000 , this corresponded to an indexed calendar year-specific $T_{t}=2.748$. This was then the value used in the age-period-cohort sur- vival model for breast cancer in the AfrD sub region. A similar process was applied to the other regions and for other cancer sites.

The period parameters $\left(T_{r}\right)$ for all the available survival data and fitted values from regression analysis were plotted against GDP per capita (international dollars) for each site and sex as shown in Figures 1,2,3,4,5,6. The largest variation in survival was observed among cancers of breast, melanoma of the skin, and hematological malignancies such as lymphoma and leukemia. For the cancers of cervix and colon and rectum, both early detection and availability of treatment determine the survival and the variation among regions were moderate. On the other hand, cancers with very poor prognosis such as liver, lung, and pancreas cancers showed very small variations across the regions regardless of the levels of national income.

\section{Model performance and validation}

In order to check the performance of the model, we graphically compared our estimated $R I S_{\alpha, t, \tau}$ for $\tau=1$ to 10 years individuals diagnosed with cancer in 1986 with the SEER $R I S_{\alpha, t, \tau}$ for $\tau=1$ to 10 years for the same cohort of individuals. We show the results obtained for males and females 55-59 years old, and for every cancer site in Figures 7,8,9. From these figures, we can observe that the model predicts very well the relative interval survivals. For those cancer sites with greater number of cases, such as colon, lung, breast, corpus uteri, and prostate cancer, the model fits very well. For those with smaller numbers such as cancers of liver and pancreas, the estimated RIS smoothes the curves for the observed RIS, also showing a very good fit.

We also tested the validity of our model when applied to other populations. We have chosen the age groups from 45 to 79 in which cancer mortality rate is relatively stable and the probability of miscoding of cause of death is small. Figures 10,11 shows the comparison between model estimates and vital registration data for six sub regions in age group 65-69 (AmrB, EurA, EurB1, EurB2, EurC, and WprA sub regions). The estimated coefficients and $\mathrm{p}-$ values for the test of Pearson's correlation by using all data 


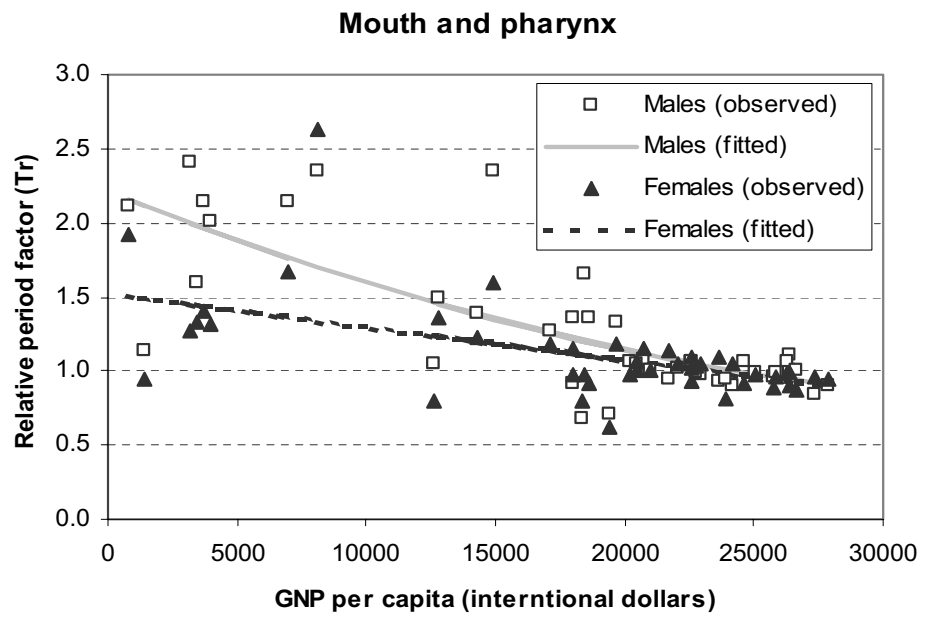

Oesophagus

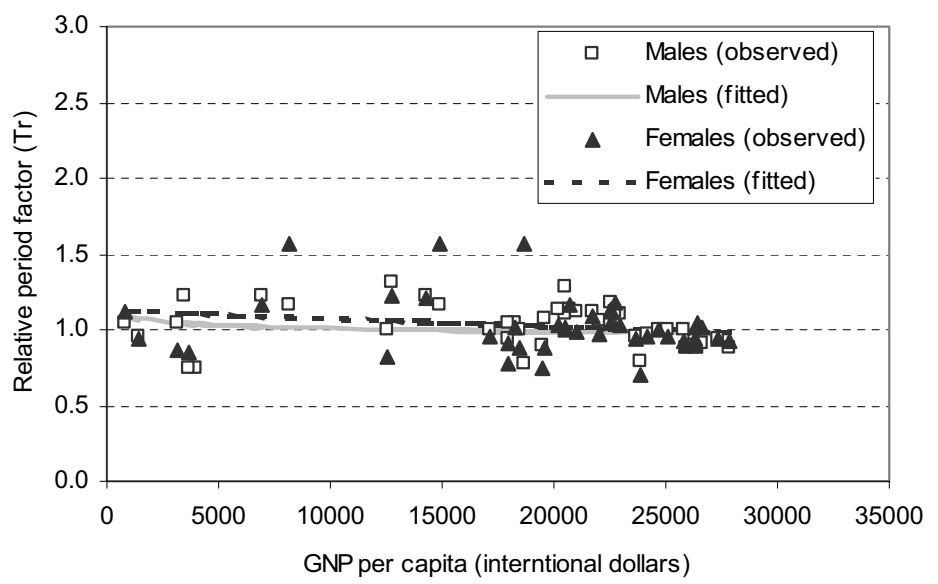

Stomach

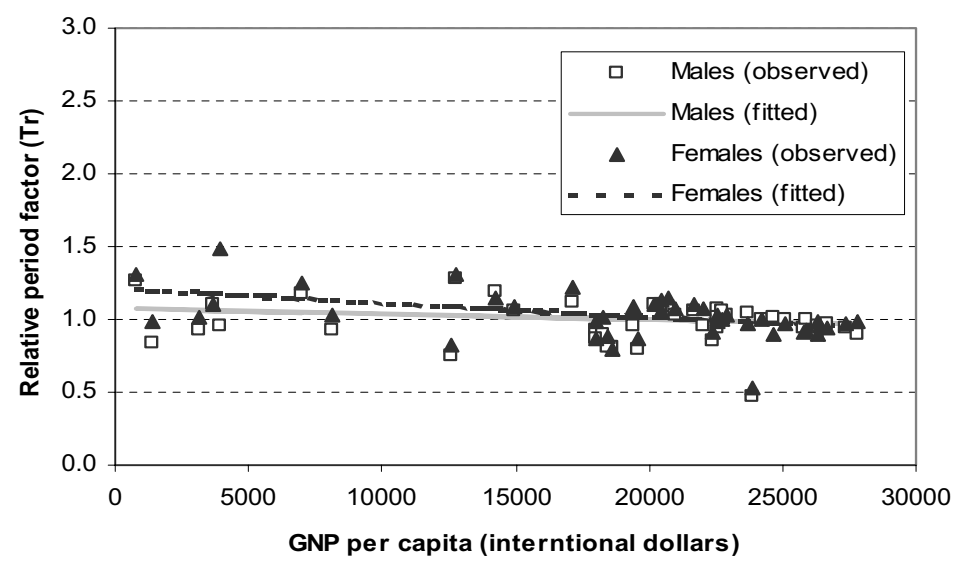

Figure I

Observed and fitted period factor by region $\left(T_{r}\right)$ versus GDP per capita (I) 
Table 6: Estimated regional period parameters $\left(T_{r}\right)$ for 2000 by cancer site and sex

\begin{tabular}{|c|c|c|c|c|c|c|c|c|c|c|c|c|}
\hline \multirow[b]{2}{*}{ Region } & \multicolumn{2}{|c|}{ Oral } & \multicolumn{2}{|c|}{ Oesophagus } & \multicolumn{2}{|c|}{ Stomach } & \multicolumn{2}{|c|}{$\begin{array}{l}\text { Colon and rec- } \\
\text { tum }\end{array}$} & \multicolumn{2}{|c|}{ Liver } & \multicolumn{2}{|c|}{ Pancreas } \\
\hline & Male & Female & Male & Female & Male & Female & Male & Female & Male & Female & Male & Female \\
\hline AfrD & 2.132 & 1.493 & 1.072 & 1.119 & 1.070 & 1.198 & 1.892 & 1.794 & 1.050 & 1.102 & 1.003 & 1.049 \\
\hline AfrE & 2.111 & 1.486 & 1.065 & 1.117 & 1.069 & 1.195 & 1.880 & 1.784 & 1.050 & 1.101 & 1.003 & 1.048 \\
\hline AmrA & 0.887 & 0.873 & 0.975 & 0.973 & 0.965 & 0.930 & 0.845 & 0.859 & 0.985 & 1.000 & 1.002 & 0.994 \\
\hline AmrB & 1.747 & 1.357 & 1.017 & 1.087 & 1.047 & 1.140 & 1.663 & 1.590 & 1.046 & 1.080 & 1.003 & 1.037 \\
\hline AmrD & 1.984 & $\mathrm{I} .443$ & 1.040 & 1.107 & 1.061 & 1.177 & 1.809 & 1.720 & 1.049 & 1.094 & 1.003 & 1.044 \\
\hline EmrB & 1.774 & 1.368 & 1.019 & 1.089 & 1.049 & $\mathrm{I} .144$ & 1.681 & 1.606 & 1.046 & 1.082 & 1.003 & 1.038 \\
\hline EmrD & 2.005 & $1.45 \mathrm{I}$ & 1.043 & 1.109 & 1.063 & 1.180 & 1.821 & 1.731 & 1.049 & 1.095 & 1.003 & 1.045 \\
\hline EurA & 1.122 & 1.059 & 0.985 & 1.017 & 0.997 & 1.011 & 1.160 & $1.14 \mid$ & 1.017 & 1.030 & 1.002 & 1.010 \\
\hline EurBI & 1.797 & 1.376 & 1.021 & 1.091 & 1.050 & 1.148 & 1.695 & 1.618 & 1.047 & 1.083 & 1.003 & 1.038 \\
\hline EurB2 & 2.069 & 1.472 & 1.054 & 1.114 & 1.066 & 1.189 & 1.857 & 1.763 & 1.050 & 1.099 & 1.003 & 1.047 \\
\hline EurC & 1.868 & 1.402 & 1.027 & 1.097 & 1.055 & 1.159 & 1.739 & 1.658 & 1.048 & 1.087 & 1.003 & 1.041 \\
\hline SearB & 1.933 & 1.426 & 1.033 & 1.103 & 1.058 & 1.169 & 1.778 & 1.693 & 1.049 & 1.091 & 1.003 & 1.043 \\
\hline SearD & 2.127 & 1.491 & I.07I & 1.118 & 1.070 & 1.197 & 1.890 & 1.792 & 1.050 & 1.102 & 1.003 & 1.048 \\
\hline WprA & 0.979 & 0.958 & 0.979 & 0.993 & 0.980 & 0.967 & 0.989 & 0.987 & 1.001 & 1.014 & 1.002 & 1.001 \\
\hline WprBI & 1.990 & 1.445 & 1.041 & 1.108 & 1.062 & I. 178 & 1.812 & 1.723 & 1.049 & 1.095 & 1.003 & 1.044 \\
\hline WprB2 & 2.095 & $\mathrm{I} .48 \mathrm{I}$ & 1.061 & 1.116 & 1.068 & 1.193 & 1.872 & 1.776 & 1.050 & 1.100 & 1.003 & 1.048 \\
\hline \multirow[t]{2}{*}{ WprB3 } & 1.967 & 1.437 & 1.038 & 1.106 & 1.060 & 1.174 & 1.799 & 1.711 & 1.049 & 1.093 & 1.003 & 1.044 \\
\hline & \multicolumn{2}{|c|}{ Lung } & \multicolumn{2}{|c|}{ Bladder } & \multicolumn{2}{|c|}{$\begin{array}{l}\text { Non-Hodgkin } \\
\text { lymphoma }\end{array}$} & \multicolumn{2}{|c|}{$\begin{array}{l}\text { Hodgkin lym- } \\
\text { phoma }\end{array}$} & \multicolumn{2}{|c|}{$\begin{array}{l}\text { Multiple mye- } \\
\text { loma }\end{array}$} & \multicolumn{2}{|c|}{ Leukaemia } \\
\hline Region & Male & Female & Male & Female & Male & Female & Male & Female & Male & Female & Male & Female \\
\hline AfrD & I.I4I & 1.212 & 3.526 & 2.844 & 1.466 & 1.581 & 2.176 & 2.419 & 1.081 & 1.213 & 1.539 & 1.493 \\
\hline AfrE & 1.139 & 1.210 & 3.492 & 2.819 & 1.459 & 1.574 & 2.160 & 2.399 & 1.080 & 1.209 & 1.532 & 1.486 \\
\hline AmrA & 0.984 & 0.995 & 0.493 & 0.653 & 0.891 & 0.913 & 0.676 & 0.557 & 0.945 & 0.907 & 0.880 & 0.875 \\
\hline AmrB & $\mathrm{I} .107$ & 1.165 & 2.864 & 2.365 & 1.340 & 1.435 & 1.849 & 2.013 & 1.052 & 1.146 & 1.395 & 1.358 \\
\hline AmrD & 1.129 & 1.195 & 3.284 & 2.669 & 1.420 & 1.528 & 2.057 & 2.271 & 1.070 & 1.188 & 1.487 & $\mathrm{I} .444$ \\
\hline EmrB & 1.110 & 1.169 & 2.915 & 2.402 & 1.350 & $\mathrm{I} .447$ & 1.874 & 2.044 & 1.054 & 1.151 & 1.406 & 1.368 \\
\hline EmrD & 1.131 & 1.198 & 3.320 & 2.695 & 1.427 & 1.536 & 2.075 & 2.293 & 1.072 & 1.192 & 1.494 & $1.45 \mid$ \\
\hline EurA & 1.031 & $1.06 \mathrm{I}$ & 1.405 & 1.312 & 1.064 & 1.114 & 1.127 & 1.117 & 0.986 & 0.999 & 1.078 & 1.061 \\
\hline EurBI & 1.112 & 1.172 & 2.956 & 2.432 & 1.358 & 1.456 & 1.894 & 2.069 & 1.056 & 1.155 & 1.415 & 1.377 \\
\hline EurB2 & 1.136 & 1.205 & 3.424 & 2.771 & 1.447 & 1.559 & 2.126 & 2.357 & 1.077 & 1.203 & 1.517 & 1.472 \\
\hline EurC & 1.118 & 1.181 & 3.083 & 2.524 & 1.382 & 1.484 & 1.957 & 2.148 & 1.061 & 1.168 & 1.443 & 1.403 \\
\hline SearB & 1.124 & 1.189 & 3.197 & 2.606 & 1.403 & 1.509 & 2.014 & 2.217 & 1.067 & 1.180 & 1.468 & 1.426 \\
\hline SearD & 1.141 & 1.212 & 3.519 & 2.839 & 1.464 & 1.580 & 2.173 & 2.415 & 1.081 & 1.212 & 1.538 & 1.492 \\
\hline WprA & 1.006 & 1.025 & 0.908 & 0.953 & 0.970 & 1.004 & 0.881 & 0.812 & 0.964 & 0.949 & 0.970 & 0.959 \\
\hline WprBI & 1.129 & 1.196 & 3.294 & 2.676 & 1.422 & 1.530 & 2.062 & 2.277 & $1.07 \mid$ & 1.189 & 1.489 & 1.446 \\
\hline WprB2 & 1.138 & 1.208 & 3.468 & 2.802 & 1.455 & 1.569 & 2.148 & 2.384 & 1.079 & 1.207 & 1.527 & $\mathrm{I} .48 \mathrm{I}$ \\
\hline \multirow[t]{2}{*}{ WprB3 } & 1.127 & 1.193 & 3.255 & 2.648 & 1.414 & 1.522 & 2.043 & 2.253 & 1.069 & 1.186 & 1.480 & 1.438 \\
\hline & \multicolumn{2}{|c|}{ Melanoma } & \multicolumn{2}{|c|}{ Miscellaneous } & Breast & Cervix & Uterus & Ovary & $\begin{array}{l}\text { Pros- } \\
\text { tate }\end{array}$ & $\begin{array}{l}\text { GDP } \\
\text { Per } \\
\text { capita }\end{array}$ & & \\
\hline Region & Male & Female & Male & Female & Female & Female & Female & Female & Male & & & \\
\hline AfrD & 3.811 & 6.596 & 1.720 & $1.74 \mid$ & 2.748 & 1.647 & 1.896 & 1.261 & 5.559 & $\mathrm{I}, \mathrm{I} 58$ & & \\
\hline AfrE & 3.775 & 6.174 & 1.709 & 1.731 & 2.725 & 1.638 & 1.885 & 1.247 & 5.505 & 1,465 & & \\
\hline AmrA & 0.452 & 0.819 & 0.718 & 0.849 & 0.657 & 0.845 & 0.881 & 1.064 & 0.647 & 28,910 & & \\
\hline $\mathrm{AmrB}$ & 3.093 & 3.311 & 1.501 & 1.546 & 2.292 & 1.472 & 1.674 & 1.149 & 4.487 & 7,217 & & \\
\hline AmrD & 3.550 & 4.680 & 1.640 & 1.670 & 2.582 & 1.583 & 1.815 & 1.196 & 5.168 & 3,367 & & \\
\hline EmrB & 3.149 & 3.431 & 1.518 & $1.56 \mathrm{I}$ & 2.327 & 1.485 & 1.692 & 1.153 & 4.570 & 6,749 & & \\
\hline EmrD & 3.589 & 4.864 & 1.652 & 1.680 & 2.606 & 1.592 & 1.827 & 1.202 & 5.226 & 3,040 & & \\
\hline EurA & $1.48 \mid$ & 1.431 & 1.019 & 1.117 & 1.286 & 1.086 & 1.186 & 1.085 & 2.125 & 20,562 & & \\
\hline
\end{tabular}


Table 6: Estimated regional period parameters $\left(T_{r}\right)$ for 2000 by cancer site and sex (Continued)

\begin{tabular}{|c|c|c|c|c|c|c|c|c|c|c|}
\hline EurBI & 3.194 & 3.535 & 1.532 & 1.573 & 2.355 & 1.496 & 1.705 & 1.157 & 4.637 & 6,371 \\
\hline EurB2 & 3.702 & 5.541 & 1.687 & I.7II & 2.678 & 1.620 & 1.862 & 1.225 & 5.395 & 2,085 \\
\hline EurC & 3.332 & 3.897 & 1.574 & 1.611 & 2.443 & 1.530 & 1.748 & 1.169 & 4.843 & 5,206 \\
\hline SearB & 3.455 & 4.297 & 1.611 & 1.644 & 2.521 & 1.560 & 1.786 & 1.183 & 5.027 & 4,168 \\
\hline SearD & 3.804 & 6.506 & 1.718 & 1.739 & 2.744 & 1.645 & 1.894 & 1.258 & 5.549 & 1,218 \\
\hline WprA & 0.922 & 1.072 & 0.855 & 0.971 & 0.943 & 0.954 & 1.020 & 1.073 & 1.319 & 25,115 \\
\hline WprBI & 3.561 & 4.728 & 1.644 & 1.673 & 2.589 & 1.585 & 1.819 & 1.198 & 5.184 & 3,277 \\
\hline WprB2 & 3.749 & 5.920 & 1.701 & 1.724 & 2.708 & 1.631 & 1.877 & 1.238 & 5.466 & 1,688 \\
\hline WprB3 & 3.519 & 4.545 & 1.631 & 1.661 & 2.562 & 1.575 & 1.806 & 1.191 & 5.122 & 3,631 \\
\hline
\end{tabular}

points in age groups from 45 to 79 were also presented. When compared with site-specific mortality distribution of the Globocan 2000 based on regional cancer registries for AFRO and SEARO regions, the model estimate also yielded consistent mortality distribution pattern (Figure 12). In all cases, the correlation coefficients were in the range of 0.91 to 0.98 , suggesting that model estimates for these regions are quite consistent with the observed cancer mortality distribution.

\section{Probability of 5-year survival and mean duration by site} The proposed model also yields RIS for various years and the mean duration of cancer by site, both of which are important inputs for the future estimation of cancer morbidity burden in terms of years lived with disability (YLDs). As an illustration of the further use of our model, Figures 13 and 14 show, respectively, the conventional 5-year survival and average duration for the female cancer patients aged 45-54 in four different sub regions (AfrE, AmrA, SearD and WprB3). Depending on the site, the chance of 5 -year survival and average duration varied considerably across the resigns, which are consistent with the estimated survival pattern above.

\section{Discussion}

As a part of the Global Burden of Disease 2000 (GBD 2000) study, we have developed a multiplicative model of relative interval survival for cancer by site based on the best available evidence from published population-based survival data from both developed and developing countries. Because of the sparseness of survival data for the developing regions of the world, we decided to use all the available data, including the most valuable cancer registry data compiled by the International Agency for Research on Cancer (IARC), national cancer registries, and lengthy time series data from the United States, to establish trends in survival with gross domestic product (GDP) per capita and then to use latest estimates of GDP per capita for developing regions, in order to estimate survival by site.

This approach takes into account, through increases in average GDP per capita for regions, the likely improvements in survival over the periods since those for which developing country survival data are available. Since our survival model adjusted for age and differences in competing mortality in each population by employing relative interval survival, the remaining variations in survival are likely to be due to differences in diagnosis and availability of appropriate treatment options. For instance, the large variation in survival was observed among cancers of bladder, breast, melanoma of the skin, and hematological malignancies such as lymphoma and leukemia for which effective therapy is established in developed regions. For the cancers of cervix and colon and rectum, both early detection and availability of treatment determine the survival and the variation among regions were moderate. On the other hand, cancers with very poor prognosis showed very small variations across the regions. The survival pattern across the regions are consistent with previous analysis based on the IARC cancer registry data [35].

The proposed model takes into account time in its three dimensions: age, calendar year (period) and time since cancer (cohort) and, due to the availability of data, the model outcome was compared the to the data reported by the US vital statistics and other regions of the world. This has given us the opportunity to evaluate our model and the data available.

However, perhaps the main advantage of this approach to estimating regional survival distributions by cancer site for developing regions is that the model correctly estimates survival and smoothes it and ensures that regional survival estimates are consistent with trends in survival across all regions, where the numbers for some cancer sites are small and highly fluctuate, and are inconsistent with other regions. For example, as can be seen in Figure $1 \mathrm{a}$, cancer registry survival estimates for some sites in some developing countries are better than recent experience in the United States, or significantly below the trend line with GDP per capita, suggesting that survival may have been overestimated due to small numbers or incomplete case follow-up. In these cases, the survival model provides survival estimates more consistent with the com- 


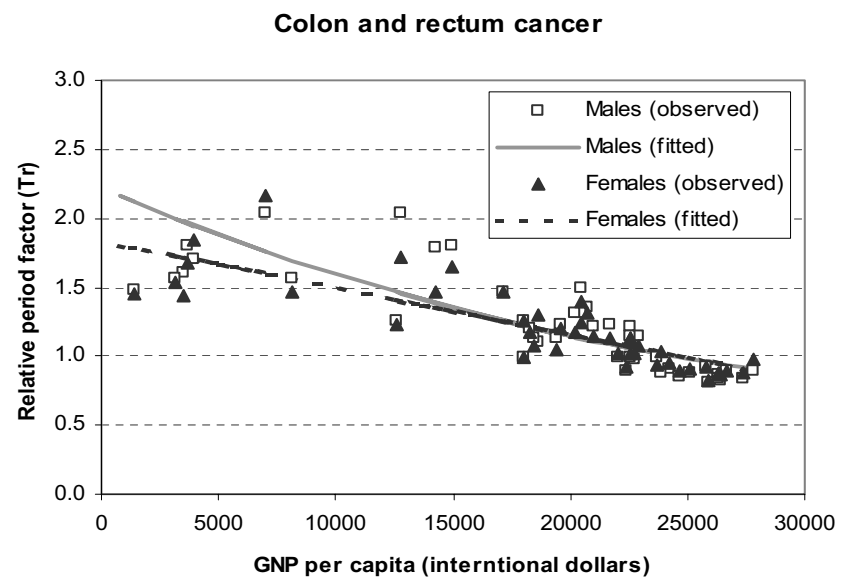

Liver cancer

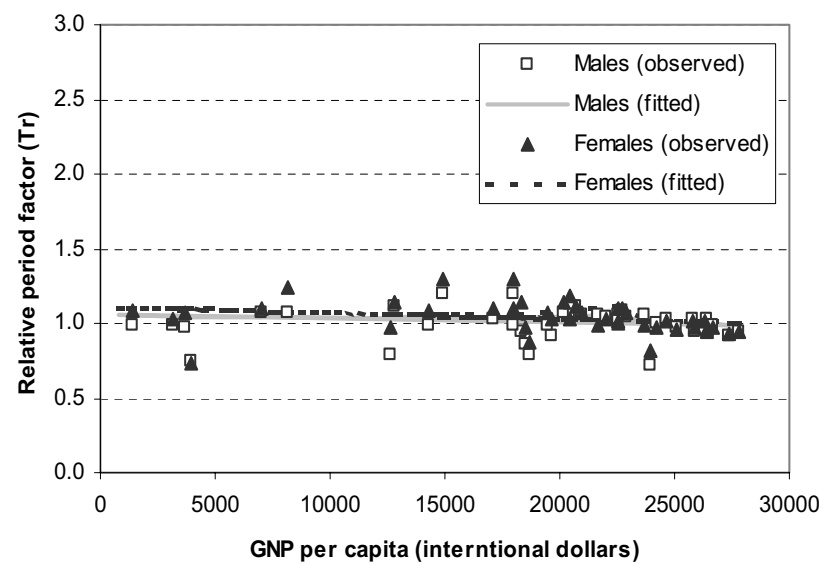

\section{Pancreas}

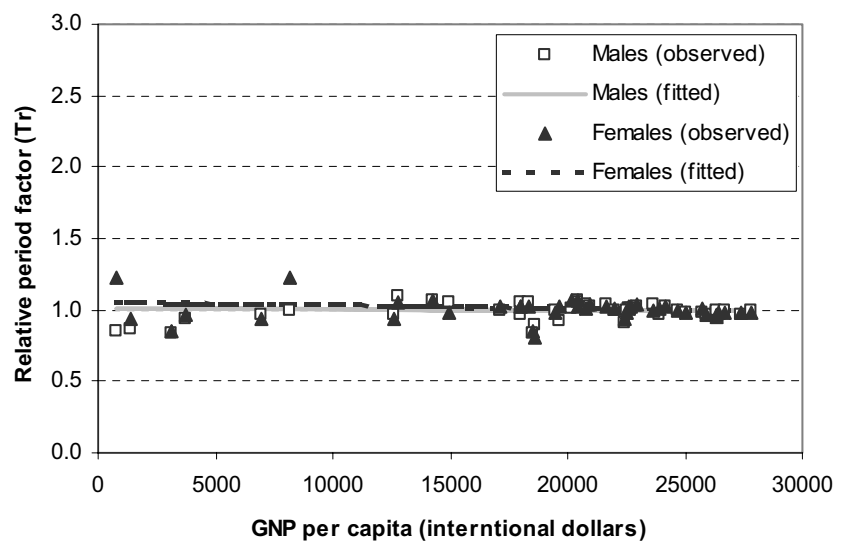

Figure 2 Observed and fitted period factor by region $\left(T_{r}\right)$ versus GDP per capita (2) 

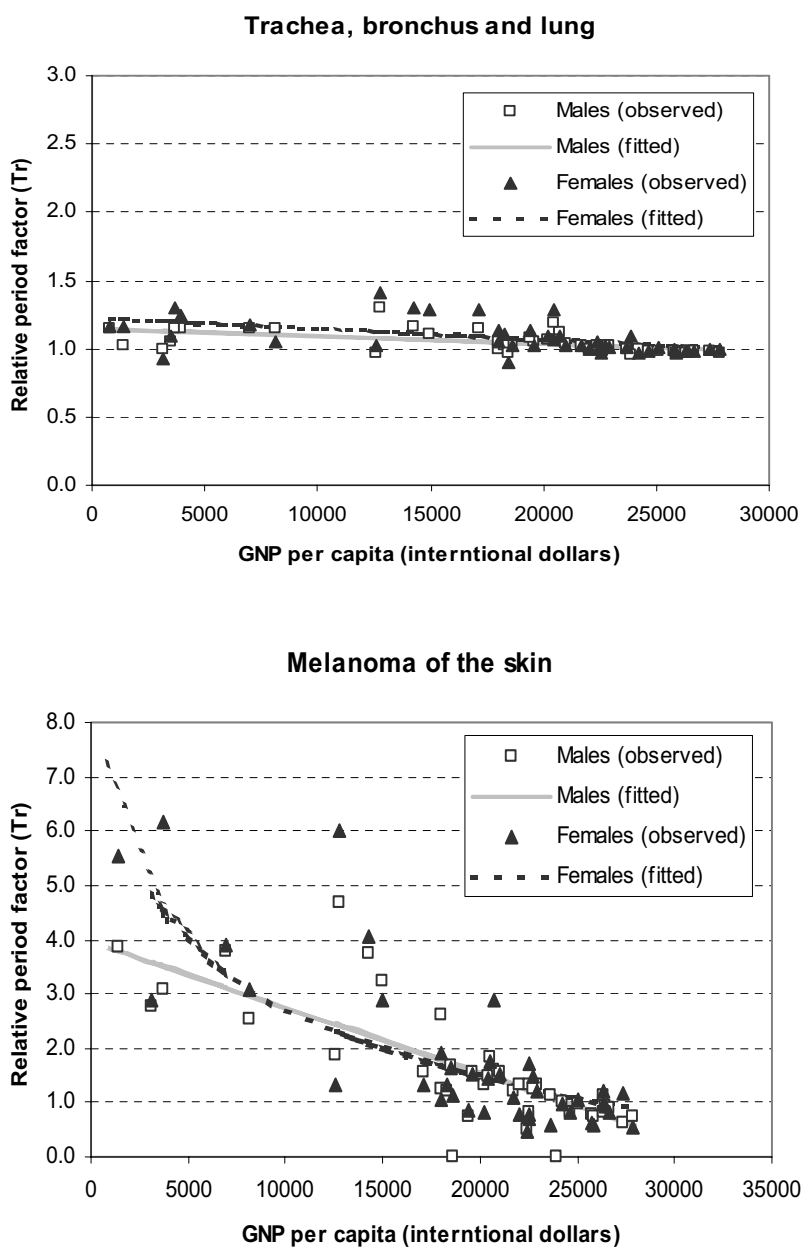

Breast

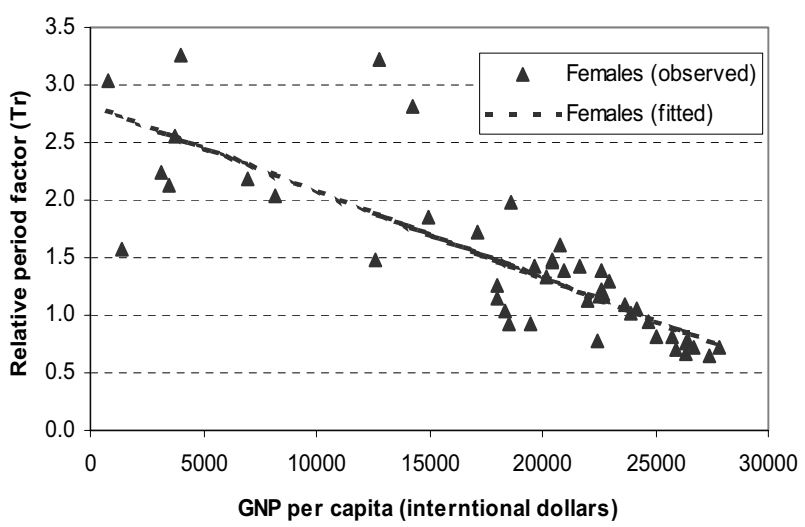

Figure 3

Observed and fitted period factor by region $\left(T_{r}\right)$ versus GDP per capita (3) 


\section{Cervix uteri}

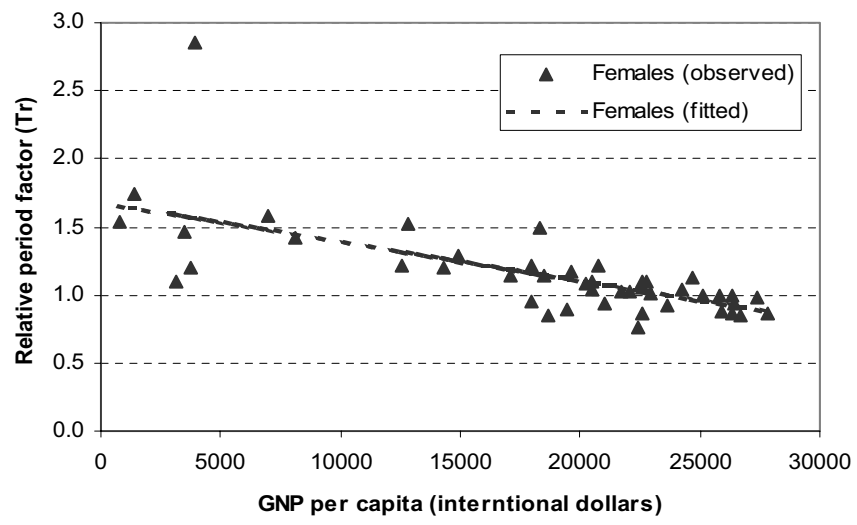

Corpus uteri

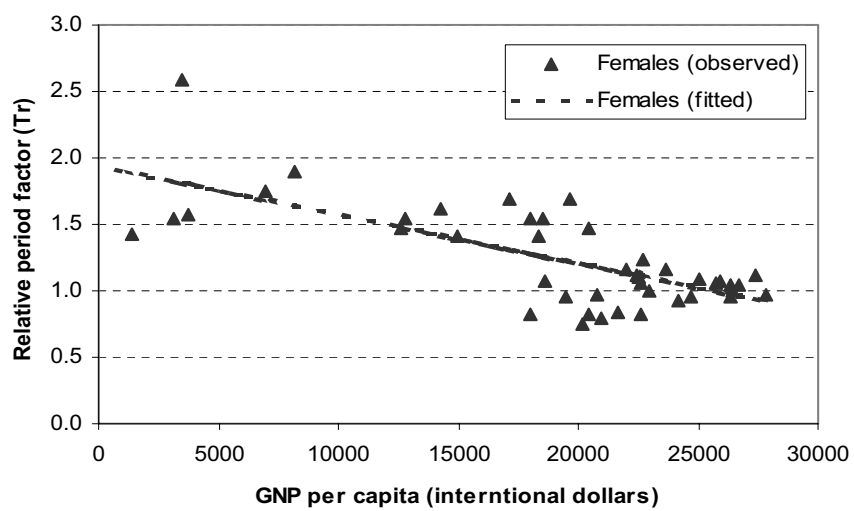

Ovary

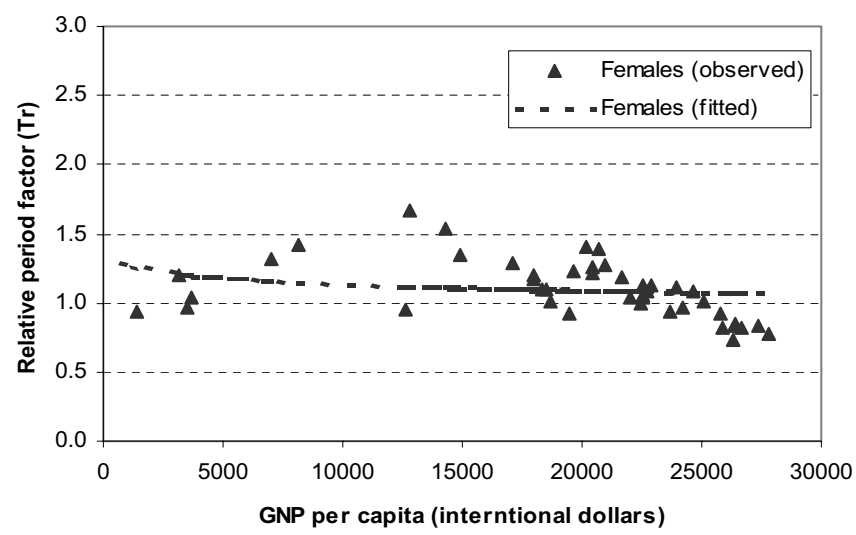

Figure 4

Observed and fitted period factor by region $\left(T_{r}\right)$ versus GDP per capita (4) 

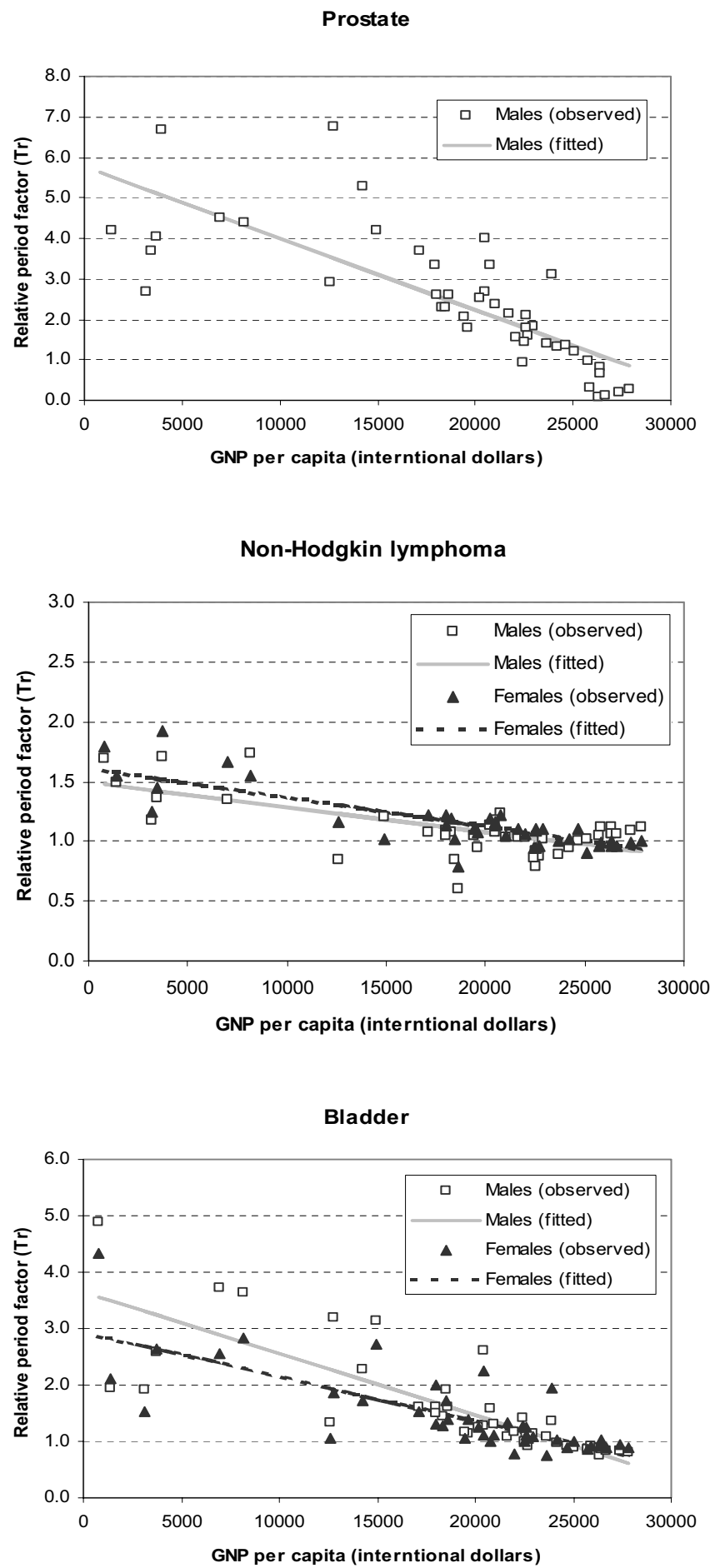

\section{Figure 5}

\section{Observed and fitted period factor by region $\left(T_{r}\right)$ versus GDP per capita (5)}




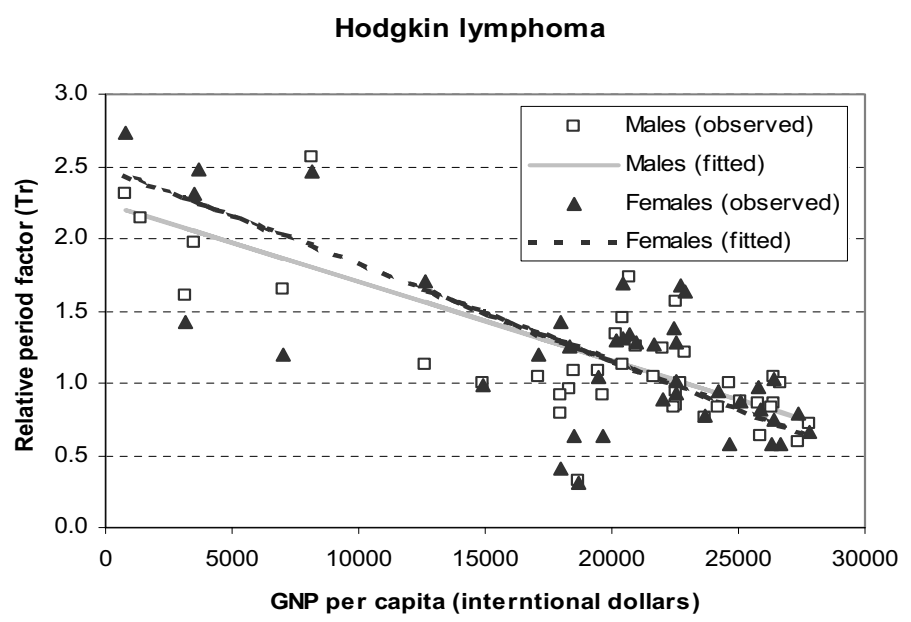

Multiple myeloma

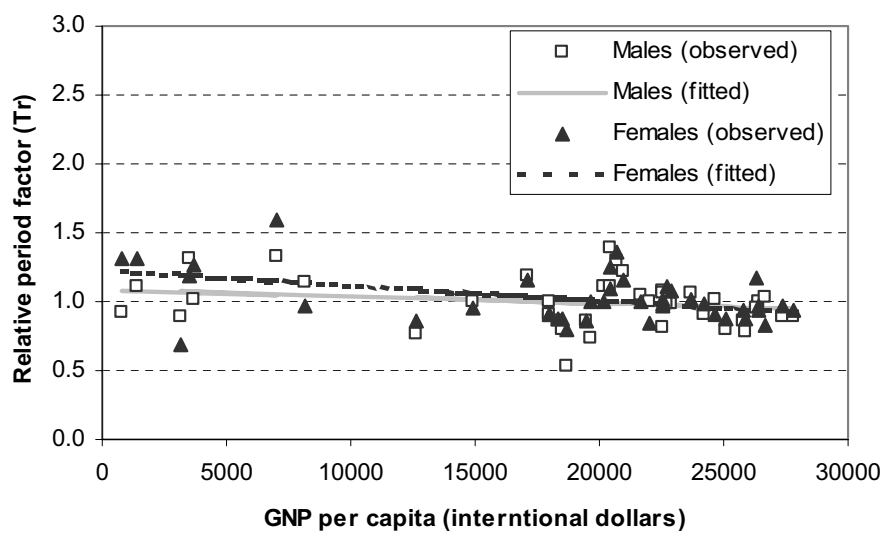

Leukaemia

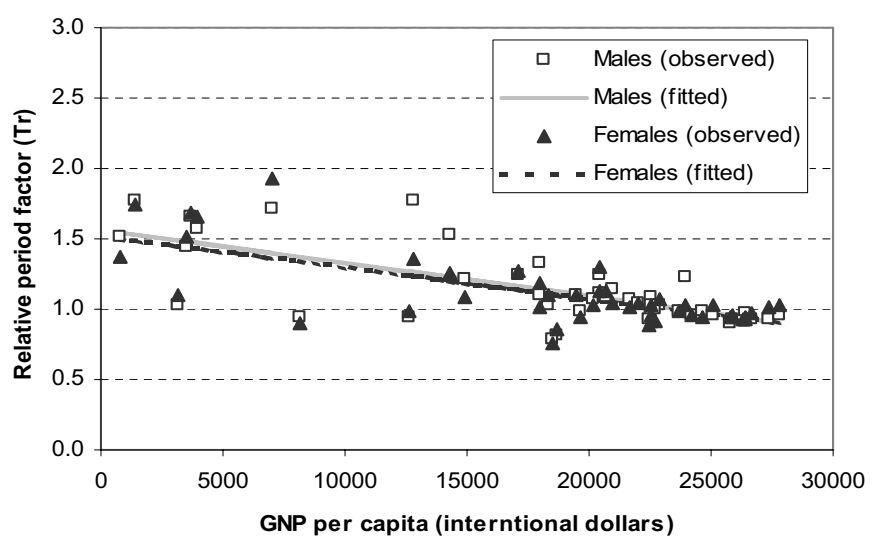

Figure 6

Observed and fitted period factor by region $\left(T_{r}\right)$ versus GDP per capita (6) 

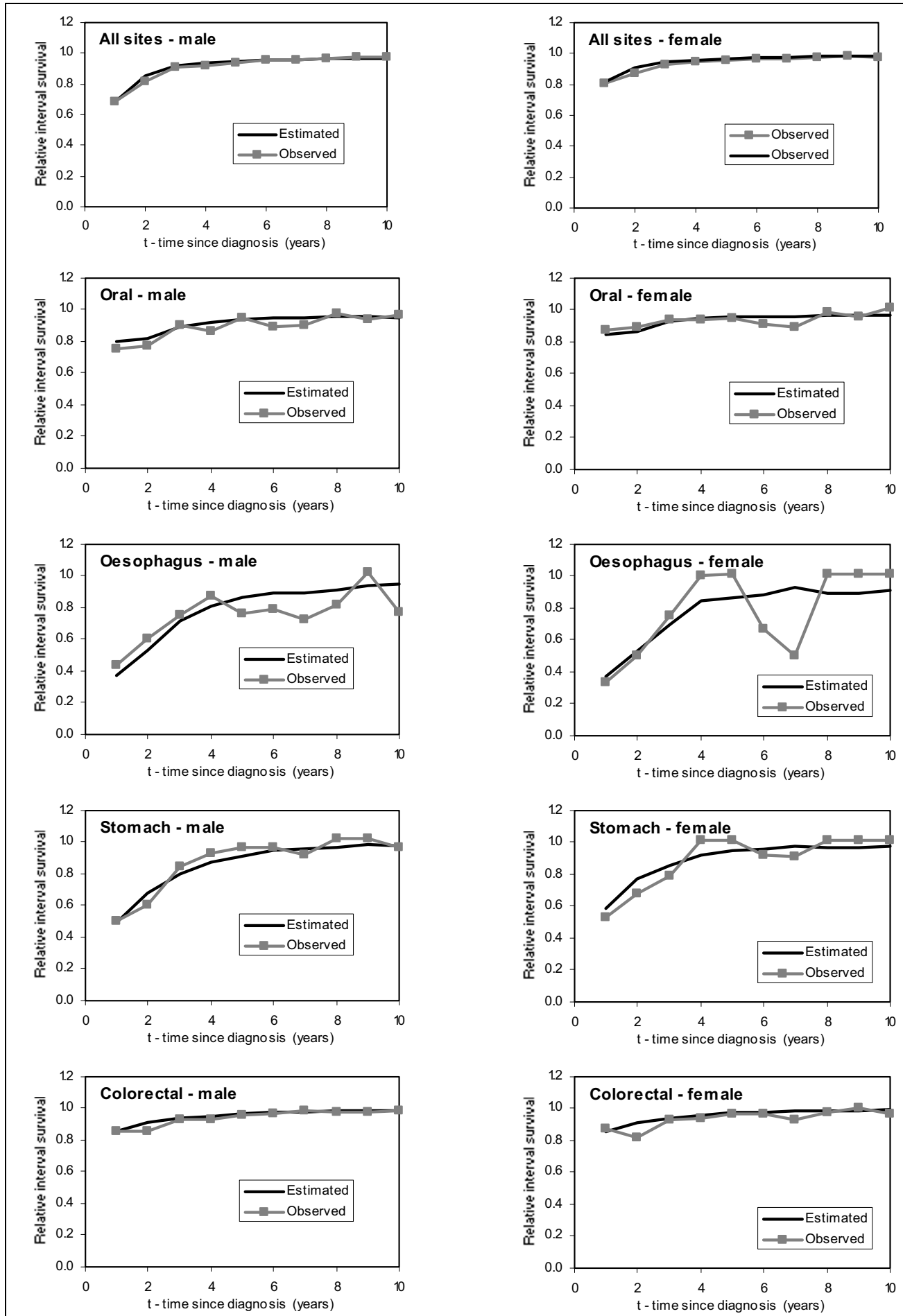

Figure 7

Comparison between predicted and observed relative interval survival for 55-59 year olds for 15 cancer sites, by sex, 1986 (I) 

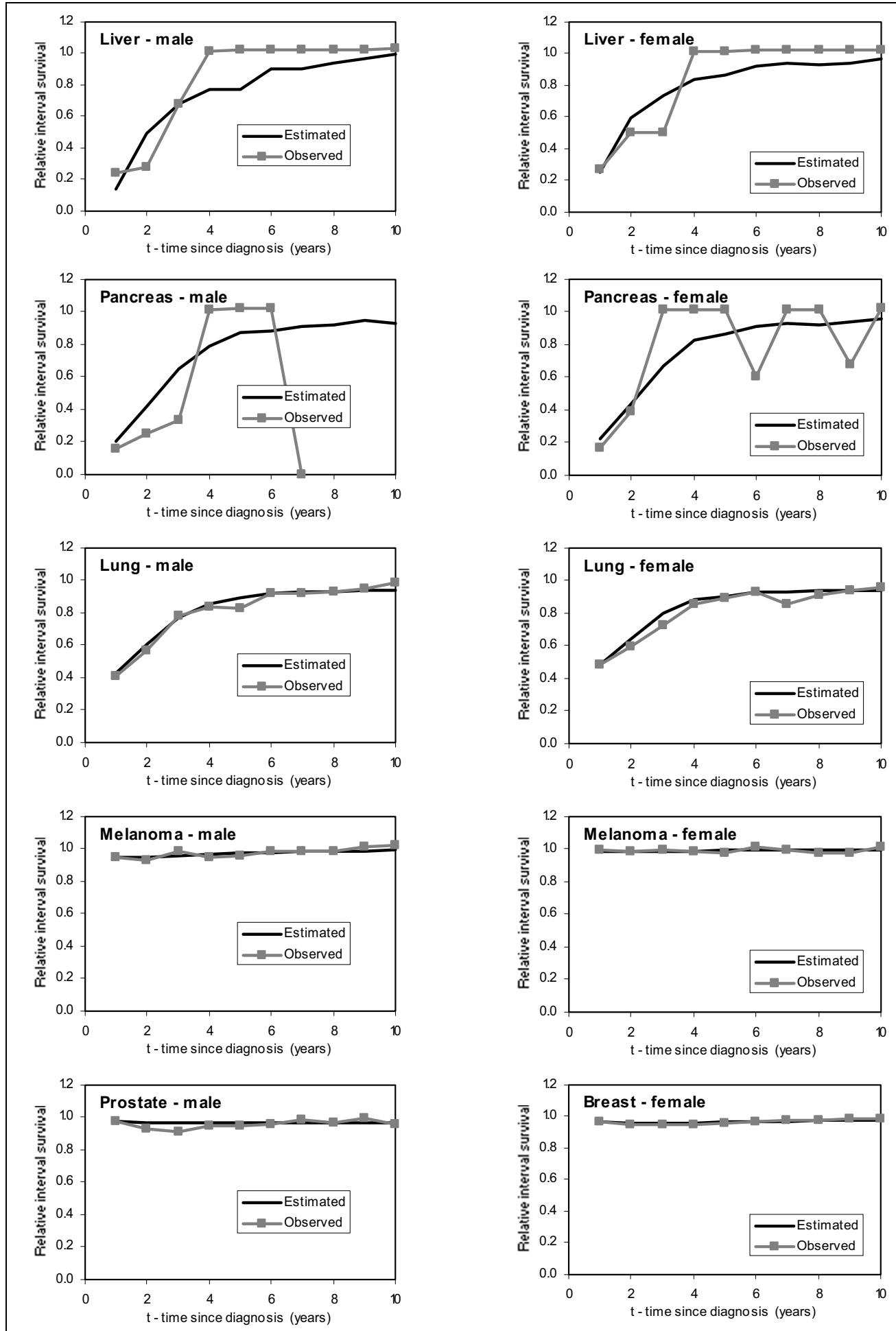

Figure 8

Comparison between predicted and observed relative interval survival for 55-59 year olds for 15 cancer sites, by sex, $1986(2)$ 


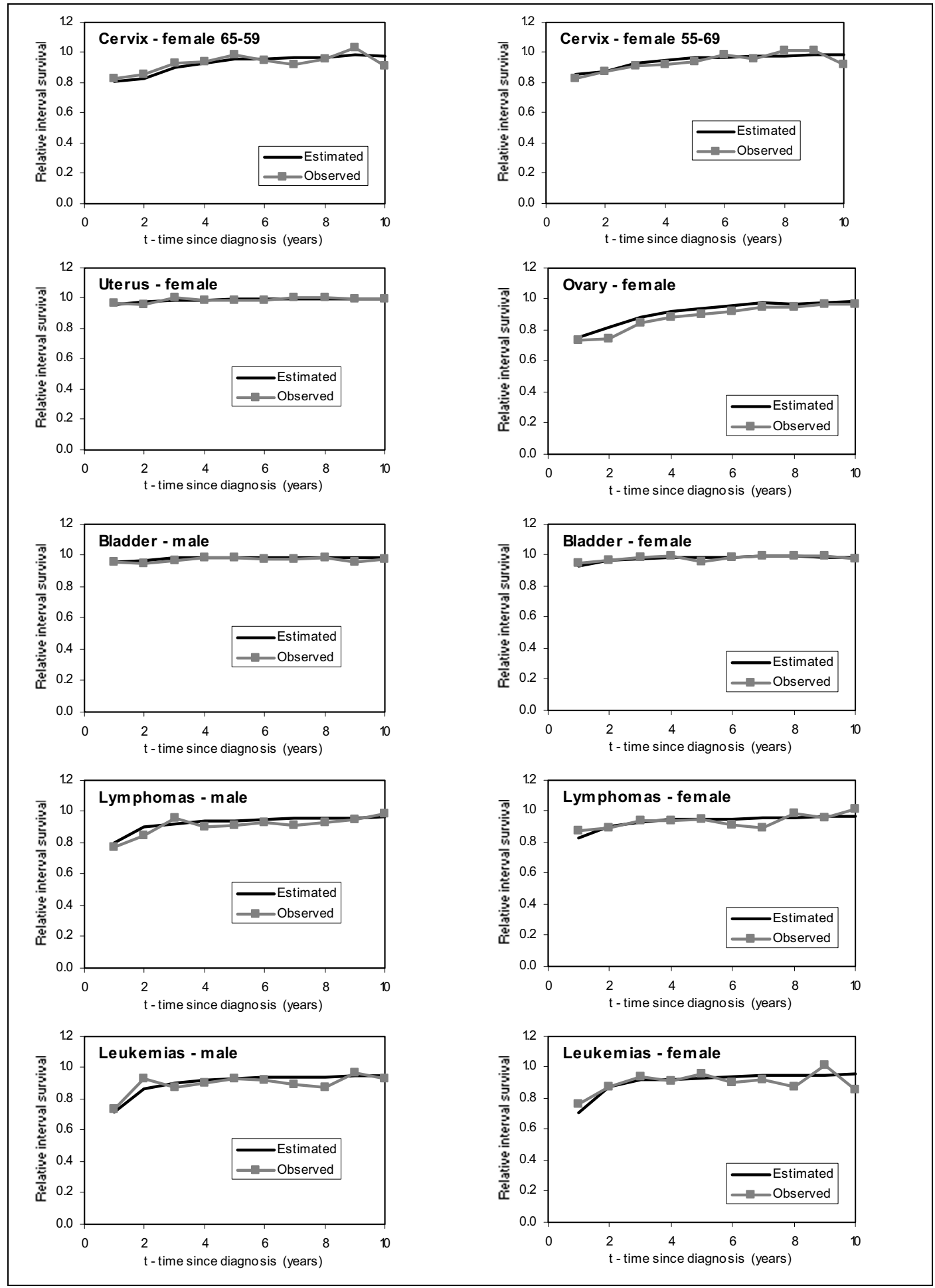

Figure 9

Comparison between predicted and observed relative interval survival for 55-59 year olds for 15 cancer sites, by sex, $1986(3)$ 
AmrB, males $\quad r=0.95(p=0.000)$

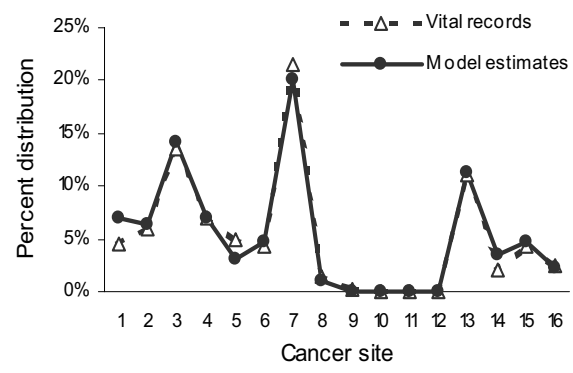

EurA, males $\quad r=0.98(p=0.000)$

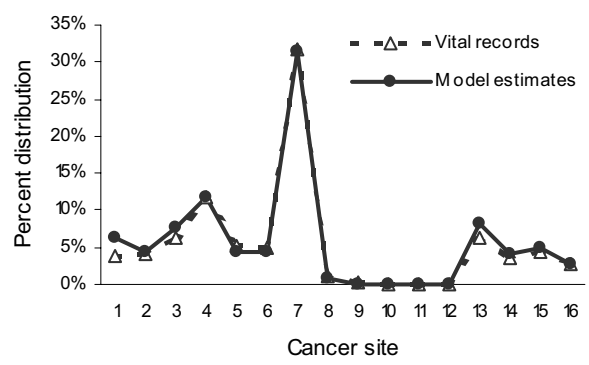

EurB1, males $\quad \mathrm{r}=0.97(\mathrm{p}=0.000)$

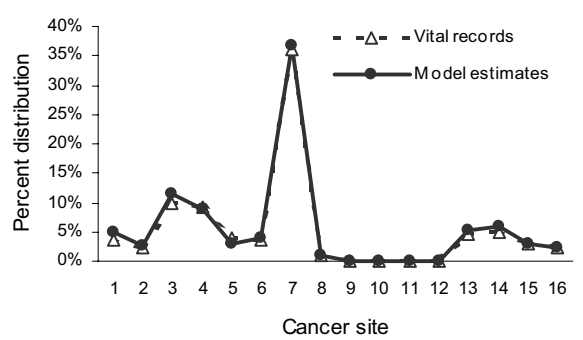

AmrB, females $\quad r=0.96(p=0.000)$

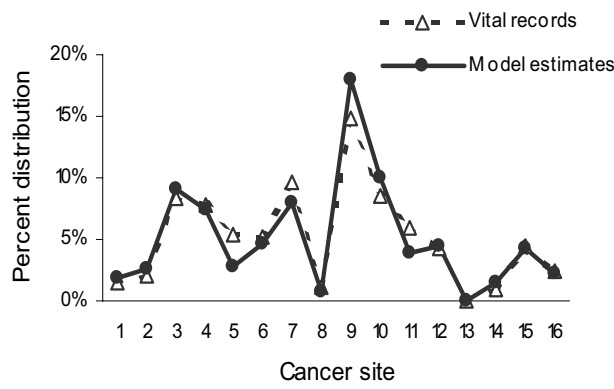

EurA, females $\quad r=0.98(p=0.000)$

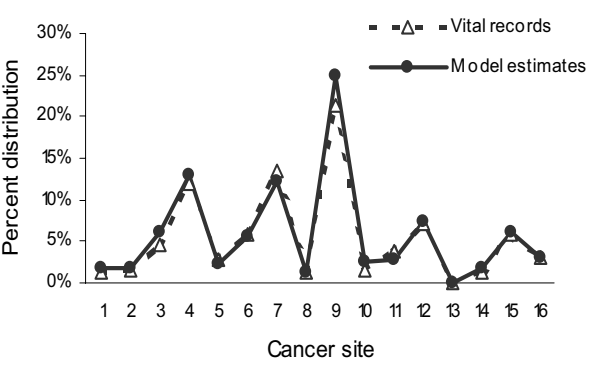

EurB1, females $\quad r=0.97(p=0.000)$

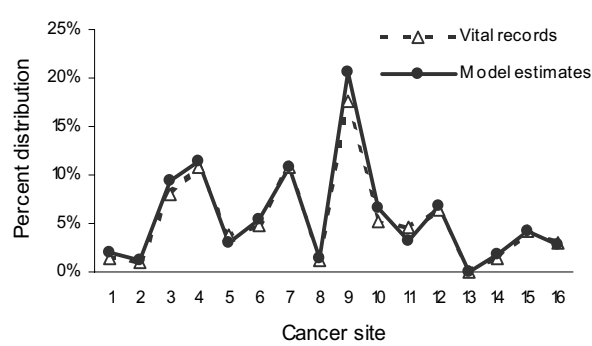

\section{Figure 10}

Mortality distribution by site: comparison between model estimates and vital registration data in three sub regions (AmrB, EurA, and EurB I) Cancer site: I = mouth and pharynx, $2=$ oesophagus, $3=$ stomach, $4=$ colon and rectum, $5=$ liver, $6=$ pancreas, $7=$ trachea, bronchus and lung, $8=$ melanoma of the skin, $9=$ breast, $10=$ cervix uteri, $I I=$ corpus uteri, 12 = ovary, 13 = prostate, $14=$ bladder, $15=$ lymphomas and multiple myeloma, $16=$ leukaemia. $r=$ Pearson's correlation coefficient when analysed with all data in age groups $45-79$. 

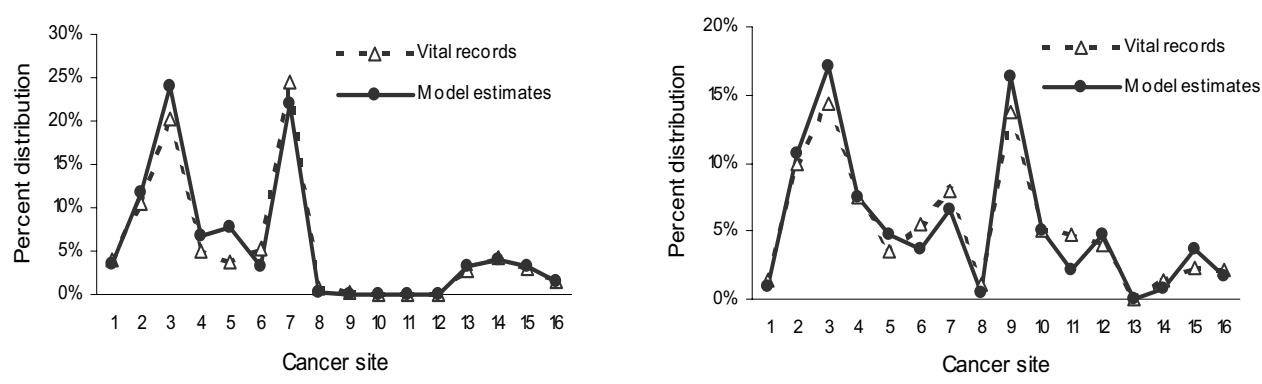

EurC, males

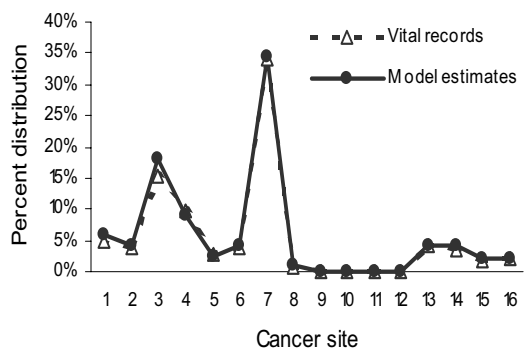

WprA, males $\quad \mathrm{r}=0.98(\mathrm{p}=0.000)$

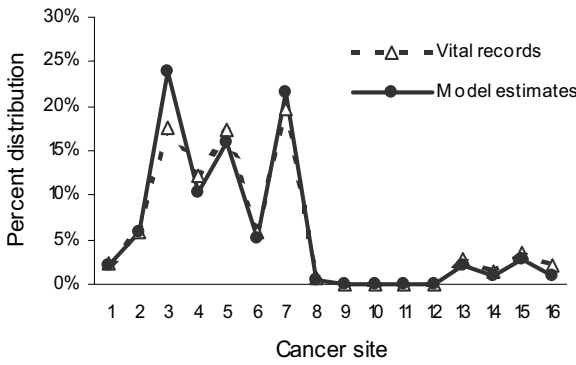

EurC, females $\quad r=0.95(p=0.000)$

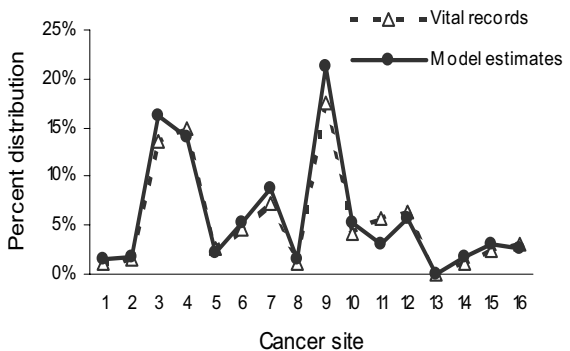

WprA, females $\quad r=0.94(p=0.000)$

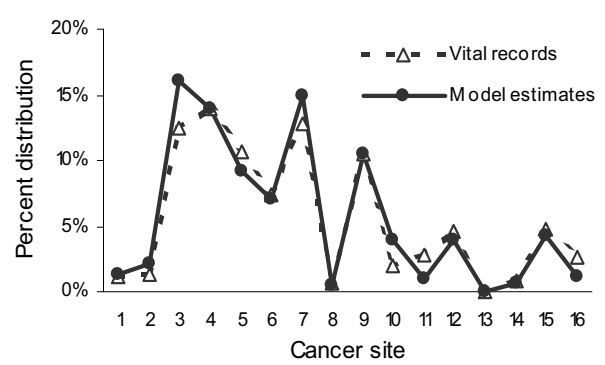

\section{Figure I I}

Mortality distribution by site: comparison between model estimates and vital registration data in three sub regions (EurB2, EurC, and WprA) Cancer site: $I=$ mouth and pharynx, $2=$ oesophagus, $3=$ stomach, $4=$ colon and rectum, $5=$ liver, $6=$ pancreas, $7=$ trachea, bronchus and lung, $8=$ melanoma of the skin, $9=$ breast, $10=$ cervix uteri, $I I=$ corpus uteri, 12 = ovary, 13 = prostate, 14 = bladder, $15=$ lymphomas and multiple myeloma, $16=$ leukaemia. $r=$ Pearson's correlation coefficient when analysed with all data in age groups $45-79$. 

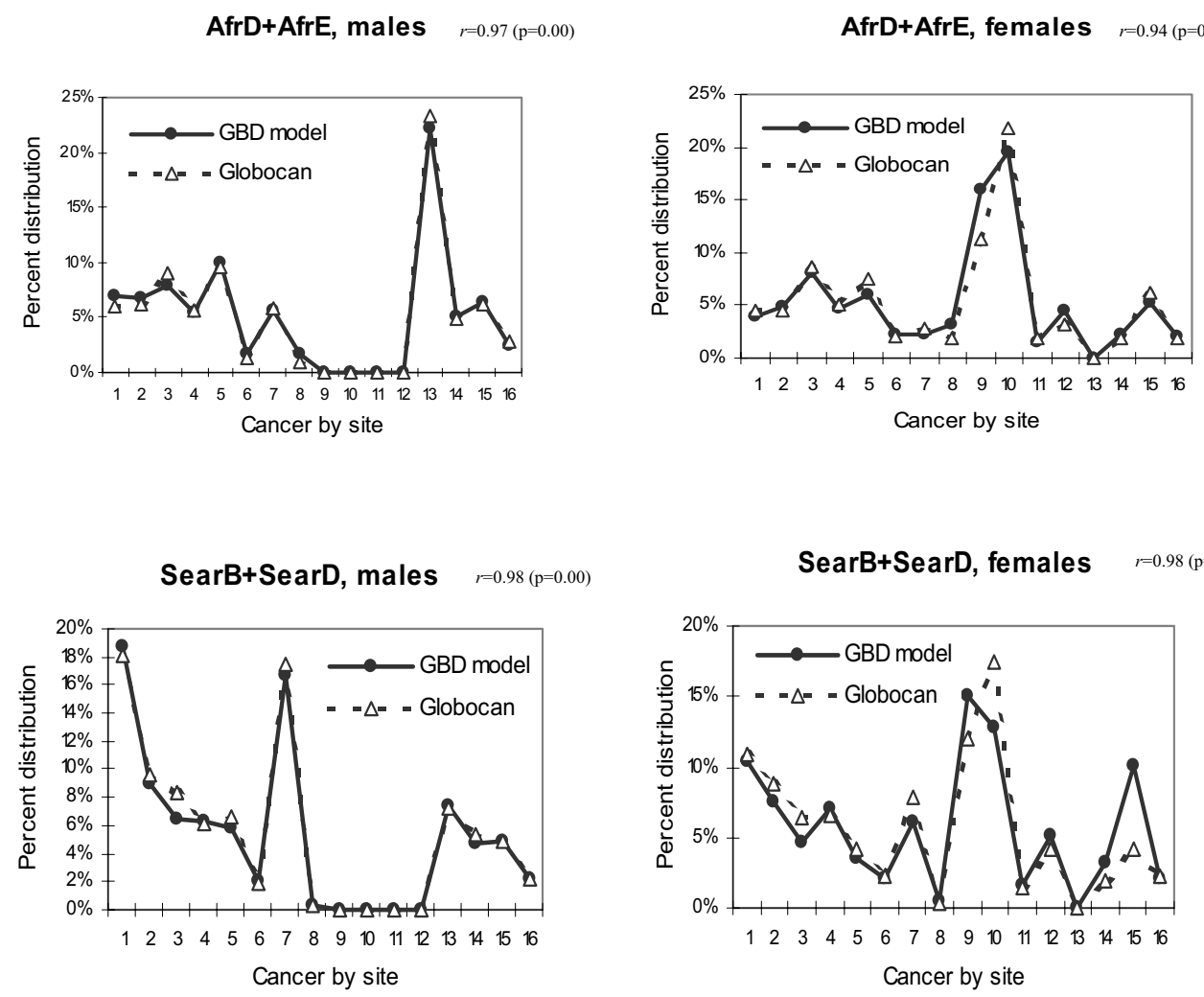

Figure 12

Mortality distribution by site: comparison between model estimates and previous estimates based on cancer registration data in AFRO and SEARO regions Cancer site: I = mouth and pharynx, 2 = oesophagus, $3=$ stomach, $4=$ colon and rectum, $5=$ liver, $6=$ pancreas, $7=$ trachea, bronchus and lung, $8=$ melanoma of the skin, $9=$ breast, $10=$ cervix uteri, II = corpus uteri, I 2 = ovary, I 3 = prostate, I 4 = bladder, I5 = lymphomas and multiple myeloma, $16=$ leukaemia. $r=$ Pearson's correlation coefficient when analysed with all data in age groups 45-79.

plete body of evidence. The second advantage of the proposed approach is that the model is flexible enough to yield the survival estimates of various age, years and period as well as mean duration of time of cancer by site. In addition to mortality and incidence estimates[36], such information is required to estimate the cancer burden in terms of disability-adjusted life years (DALYs) in the future analysis for the GBD 2000[1].

The main limitations for applying this model were the relative lack of region-specific survival data and very few, and probably not always representative, regional cancer incidence data for some developing regions. We assumed that cancer incidence reported by a few countries of one region or sub region would represent the incidence of the whole area, which may not always be the case.

It is suggested that model-based estimates of cancer mortality in the previous GBD 1990 study did not reflect the actual profile of cancer recorded at the regional registries, in particular of site-specific cancer mortality distribution $[3,5,37]$. Although population-based estimates from cancer registry data should be incorporated, they may not to be representative of the whole countries they should represent. Such estimates are sometimes restricted to certain geographic areas and also related to the extent of health care and surveillance system. Furthermore, several devel- 


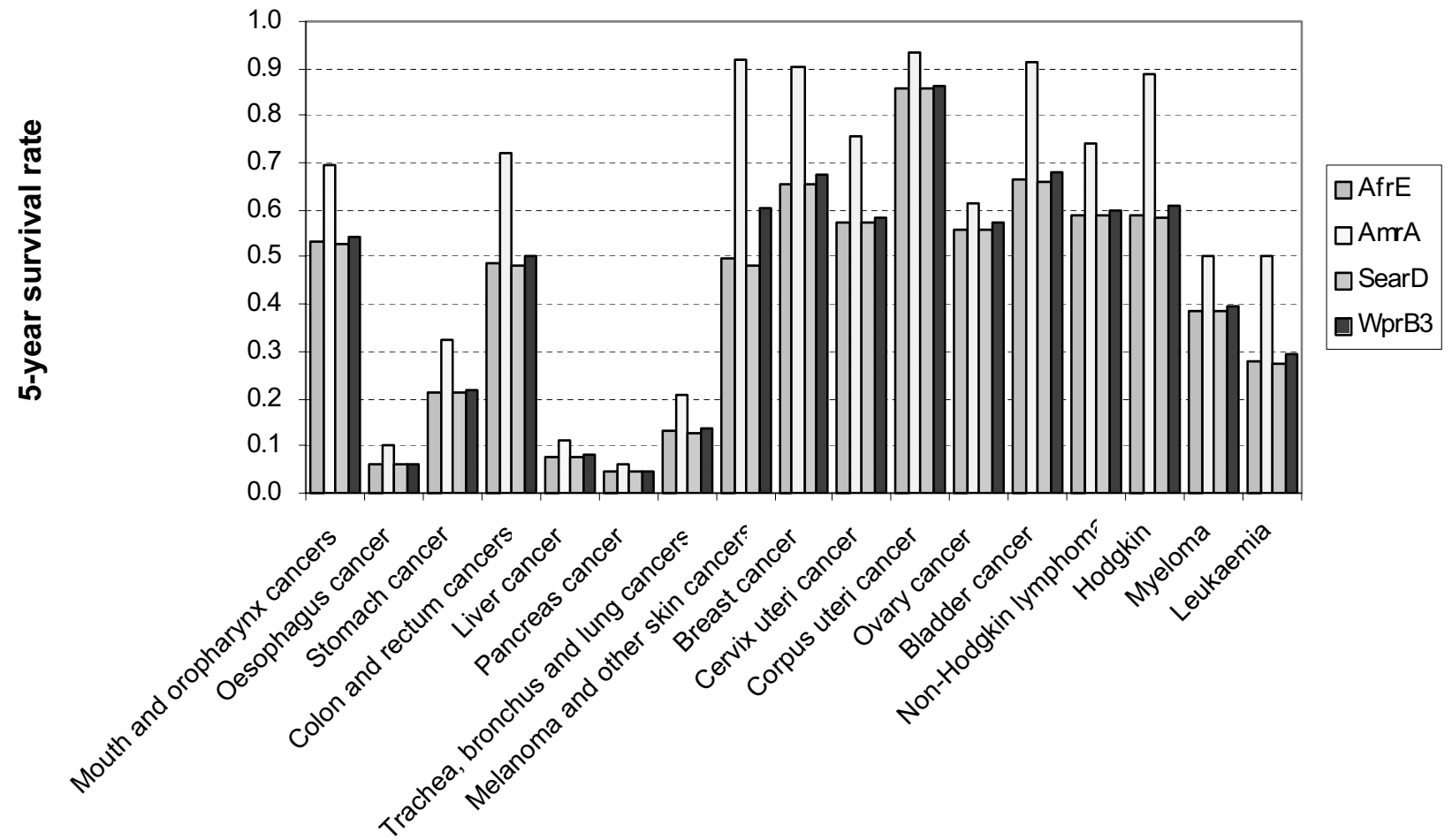

Figure 13

Five-years survival rate by site in four sub regions, females, age 45-54

oping regions of the world were not included in these estimates, and the need to produce model-based estimates would persist.

Contrary to the previous GBD 1990 model, the present survival model specifically developed for the GBD 2000 incorporated all available survival information obtained from registries and corrected for possible bias. The model was used to estimate the distribution of death by site not the actual magnitude of cancer mortality in regions where no or little data on detailed cause of death is available. In fact, the model estimates were quite comparable to the mortality distribution estimated from vital registration records. Furthermore, when for the regions where vital records are not available, our model was consistent with the Globocan 2000 estimates based on the regional registries [6].

\section{Conclusions}

The survival model presented offers a new approach to the calculation of the number and distribution of deaths for areas where mortality data are either scarce or unavailable. It can also be applied in areas with good quality data, but where there are small numbers of some site-specific cancers. The model is flexible enough to estimate some of the parameters required to estimate the cancer burden. In our future work, we will attempt to collect further information on survival and incidence from more individual countries in order to improve our estimates, with more precise inputs for the model.

\section{Competing Interests}

None declared. 


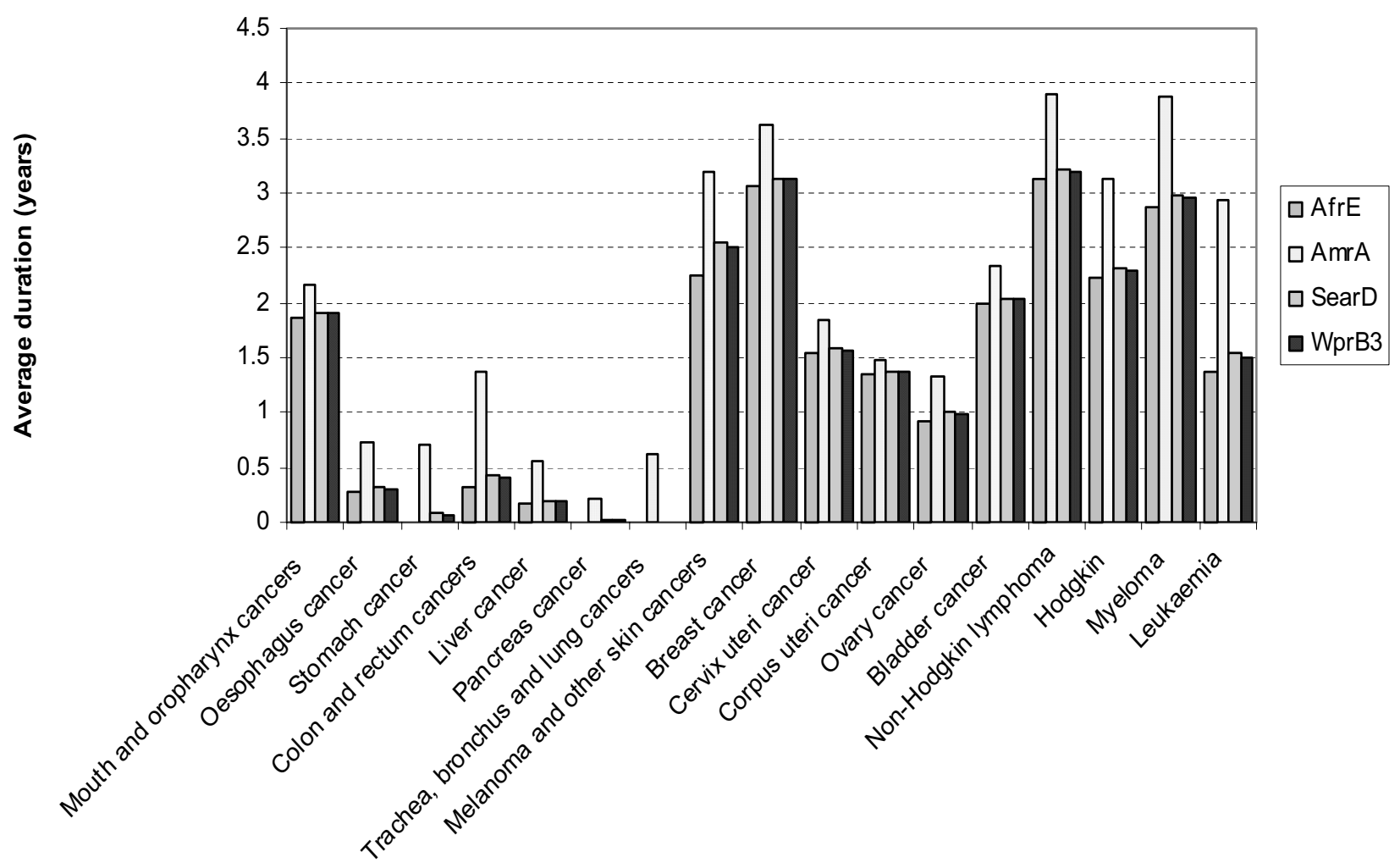

Figure 14

Average duration of patients who die from cancer in four sub regions, females, age 45-54

\section{Author's Contributions}

CDM participated in the design of the study, analysed the data, and drafted the initial manuscript. KS participated in the design of the study, performed statistical analyses, and drafted the revised manuscript. CBP implemented the initial version of the survival model, carried out the data compilation, and drafted the initial manuscript. ADL participated in the design of the study and in the mortality analysis. CJLM conceived of the study and participated in its design and coordination. All authors read and approved the final manuscript.

\section{Acknowledgements}

Many people are contributing to the analysis of cancer incidence and mortality for the GBD 2000 both inside and outside WHO. We wish to particularly acknowledge the contributions of staff within the Global Program on Evidence for Health Policy who have contributed to the estimation of total cancer deaths for the year 2000: Majid Ezzati, Brodie Ferguson, Mie Inoue, Rafael Lozano, Doris Ma Fat, and Lana Tomaskovic. We would also like to than the valuable comments from Hideaki Tsukuma and Akira Oshima of the Osaka Prefectural Department of Public Health and Welfare. We thank staff of the International Agency for Research on Cancer (IARC) for provision of data, advice on survival analyses carried out by IARC and methods used to estimate cancer incidence and mortality for Globocan 2000, particularly Max Parkin, Jacques Ferlay, Paola Pisani and Fred Bray.

\section{References}

I. Murray CJL, Lopez AD and Mathers CD The Global Burden of Disease $\mathbf{2 0 0 0}$ project: aims, methods and data sources. Geneva, World Health Organization 200I,

2. Pisani P, Parkin DM and Bray F Estimates of the worldwide mortality from 25 cancers in 1990. Int J Cancer 1999, 83(I): 18-29

3. Murray $\mathrm{CJL}$ and Lopez AD Mortality by cause for eight regions of the world: global burden of disease study. Lancet 1997, 349: $1269-1276$

4. Parkin DM The global burden of cancer. Semin Cancer Biol 1998 , 8:219-235

5. Parkin DM, Pisani $P$ and Ferlay J Estimates of the worldwide incidence of 25 major cancers in 1990. Int J Cancer 1999, 80(6):827841 
6. Ferlay J, Bray F and Pisani P Globocan 2000: Cancer Incidence, Mortality and Prevalence Worldwide, Version I.0. IARC Cancer Base No. 5. Lyon, IARC Press 200I,

7. Parkin DM, Whelan SL and Ferlay J Cancer incidence in five continents. IARC Scientific Publications No. 143. Lyon, International Agency for Research on Cancer 1997.

8. Verdecchia A, Capocaccia R and Egidi V A method for the estimation of chronic disease morbidity and trends from mortality data. Stat Med 1989, 8:201-216

9. Lundberg $O$ Methods of estimating morbidity and prevalence of disablement by use of mortality statistics. Acta Psychiatrica Scandinavica 1973, 49:324-331

10. Wingo PA, Lndis $S$ and Parker $S$ Using cancer registry and vital statistics data to estimate the number of new cancer cases and deaths in the United States for the upcoming year. Journal of Regulation and Management 1998, 25:43-5I

II. Ries LAG, Eisner MP and Kosary CL SEER Cancer Statistics Review, 1973-1999. Bethesda, MD, National Cancer Institute 2002,

12. Sitas F, Bezwoda WR and Levin $\vee$ Association between human immunodeficiency virus type $I$ infection and cancer in the black population of Johannesburg and Soweto, South Africa. Br J Cancer 1997, 75: I 704-1707

13. Mueller N Overview of the epidemiology of malignancy in immune deficiency. J Acquir Immune Defic Syndr 1999, 21 (Suppl I):S5-10

14. Smith C, Lilly S and Mann K AIDS-related malignancies. Ann Med 1998, 30:323-344

15. Serraino $D$ The spectrum of Aids-associated cancers in Africa. AIDS 1999, 13:2589-2590

16. Sitas E, Pacella-Norman R and Carrara H The spectrum of HIV-I related cancers in Sourth Africa. Int I Cancer 2000, 88:489-492

17. Parkin DM, Garcia-Giannoli $\mathrm{H}$ and Raphael M Non-Hodgkin lymphoma in Uganda: a case-control study. AIDS 2000, I 4:2929 2936

18. Newton R, Grulich A and Sindikubwabo B Cancer and HIV infection in Rwanda. Lancet 1995, 345: 1378-1379

19. Sitas F, Madhoo J and Wessie I Cancer in South Africa, 19931995. Johannesburg, National Cancer Registry of South Africa, South African Institute for Medical Research 1998

20. Chokunonga E, Levy LM and Bassett MT Cancer incidence in the African population of Harare, Zimbabwe: second results from the cancer registry 1993-1995. Int / Cancer 2000, 85:54-59

21. Wabinga HR, Parkin DM and Wabwire-Mangen F Cancer in Kampala, Uganda, in 1989-91: changes in incidence in the era of AIDS. Int J Cancer 1993, 54:26-36

22. Newton R, Ngilimana PJ and Grulich A Cancer in Rwanda. Int J Cancer 1996, 66:75-81

23. Bah E, Hall AJ and Inskip HM The first 2 years of the Gambian National Cancer Registry. Br J Cancer 1990, 62:647-650

24. Australian Institute of Health and Welfare (AIHW) Cancer survival in Australia, 200 I. Part I: National summary statistics. Canberra, Australian Institute of Health and Welfare 200I,

25. Martin AA, Galan YH and Rodriguez AJ The Cuban National Cancer Registry: 1986-1990. Eur J Epidemiol 1998, 14:287-297

26. Brooks SE, Hanchard $B$ and Wolff $C$ Age-specific incidence of cancer in Kingston and St. Andrew, Jamaica, 1988-1 992. West Indian Med J 1995, 44:102-105

27. Adib SM, Mufarrij AA and Shamseddine AI Cancer in Lebanon: an epidemiological review of the American University of Beirut Medical Center Tumor Registry (1983-1994). Ann of Epidemiol |998, 8:46-51

28. United Nations World Population Prospects The 1998 revision Volume III: Analytical Report. New York, United Nations 2000,

29. Surveillance, Epidemiology, and End Results (SEER) Program Public-Use Data (1973-1999) National Cancer Institute, DCCPS, Surveillance Research Program, Cancer Statistics Branch, released April based on the November 2002

30. Eisenberg H, Sullivan PD and Connelly RR Cancer in Connecticut. Survival experience. Hartford, Connecticut State Department of Health 1968 ,

31. Sankaranarayanan R, Black RJ and Parkin DM Cancer survival in developing countries. IARC Scientific Publications No. Lyon, International Agency for Research on Cancer 1998 ,

32. Berrino $F$, Capocaccia $R$ and Estève J Survival of cancer patients in Europe: the EUROCARE-2 study. IARC Scientific Publications No. 151. Lyon, International Agency for Research on Cancer 1999,
33. Osaka Prefectural Department of Public Health and Welfare, Osaka Medical Association, Osaka Medical Center for Cancer and Cardiovascular Diseases Annual Report of Osaka Cancer Registry No. 64-Cancer Incidence and Medical Care in Osaka in 1998 and the Survival in 1994. Osaka, Japan, Osaka Prefectural Department of Public Health and Welfare 200I,

34. Greene WH Econometric analysis. New York, Prentice Hall 1997,

35. Sankaranarayanan R, Swminathan R and Black RJ Global variations in cancer survival. Cancer 1996, 78:246I-4

36. Shibuya $K$, Mathers $C D$ and Boschi-Pinto $C$ Global and regional estimates of cancer mortality and incidence by site: II. Results for the Global Burden of Disease 2000. BMC Cancer 2002, 37

37. Gupta P, Sankaranarayanan R and Ferlay J Cancer death in India: is the model-based approach valid? Bull World Health Organ 1994, 72:943-944

\section{Pre-publication history}

The pre-publication history for this paper can be accessed here:

http://www.biomedcentral.com/1471-2407/2/36/prepub
Publish with Biomed Central and every scientist can read your work free of charge

"BioMed Central will be the most significant development for disseminating the results of biomedical research in our lifetime. "

Sir Paul Nurse, Cancer Research UK

Your research papers will be:

- available free of charge to the entire biomedical community

- peer reviewed and published immediately upon acceptance

- cited in PubMed and archived on PubMed Central

- yours - you keep the copyright
BioMedcentral 